\title{
CHEMILUMINESCENT DETECTION OF METALS IN LIQUID CHROMATOGRAPHY
}

Byron Malcolm Strom

M.S. Thesis Submitted to Iowa State University

\author{
Ames Laboratory, USAEC \\ Iowa State University \\ Ames, Iowa 50010
}

Date Transmitted: October 1974

This report was prepared as an account of work
sponsored by the United States Government, Neither
the United States nor the United States Atomic Energy
Commission, nor any of their employees, nor any of
their contractors, subcontractors, or their employees,
makes any warranty, express or implied, or assumes any
legal liability or responsibility for the accuracy, com-
pleteness or usefulness of any information, apparatus,
product or process disclosed, or represents that its use
would not infringe privately owned rights.

PREPARED FOR THE U.S. ATOMIC ENERGY COMMISSION DIVISION OF RESEARCH UNDER CONTRACT NO. W-7405-eng-82 


\section{DISCLAIMER}

This report was prepared as an account of work sponsored by an agency of the United States Government. Neither the United States Government nor any agency Thereof, nor any of their employees, makes any warranty, express or implied, or assumes any legal liability or responsibility for the accuracy, completeness, or usefulness of any information, apparatus, product, or process disclosed, or represents that its use would not infringe privately owned rights. Reference herein to any specific commercial product, process, or service by trade name, trademark, manufacturer, or otherwise does not necessarily constitute or imply its endorsement, recommendation, or favoring by the United States Government or any agency thereof. The views and opinions of authors expressed herein do not necessarily state or reflect those of the United States Government or any agency thereof. 


\section{DISCLAIMER}

Portions of this document may be illegible in electronic image products. Images are produced from the best available original document. 
This report was prepared as an account of work sponsored by the United States Government. Neither the United States nor the United States Atomic Energy Commission, nor any of their employees, nor any of their contractors, subcontractors, or their employees, makes any warranty, express or implied, or assumes any legal liability or responsibility for the accuracy, completeness or usefulness of any information, apparatus, product or process disclosed, or represents that its use would not infringe privately owned rights.

Available from: National Technical Information Service Depar timent A

Springfield, VA 22151

Price: Microfiche \$2.2.5

Paper copy $\$ 5.45$ 
Chemiluminescent detection of metals

in 1iquid chromatography

by

Byron Malcolm Strom

\author{
A Thesis Submitted to the \\ Graduate Faculty in Partial Fulfillment of \\ The Requirements for the Degree of \\ MASTER OF SCIENCE \\ Department: Chemistry \\ Major: Analytical Chemistry
}

Approved:

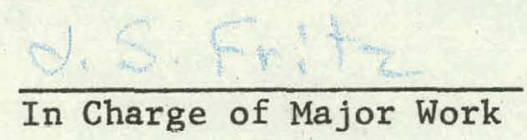

For the Major Department

For the Graduate College

Iowa State University
Ames, Iowa 


\section{$\mathrm{i} \mathrm{v}$}

TABLE OF CONTENTS

Page

Abstract

INTRODUCTION

$\mathrm{V}$

1

Statement of the Problem 1

The Luminol Reaction $\quad 5$

EXPERIMENTAL $\quad \ldots \quad 10$

Apparatus 10

Chromatograph 10

Detector. $\quad 12$

Photomultiplier tube housing 12

Flow cell 12

$\begin{array}{ll}\text { Column } & 15\end{array}$

Reagents 15

Luminol-buffer solution $\cdot 15$

Hydrogen peroxide 15

Methanol-hydrochloric acid solutions 16

RESULTS AND DISCUSSION 17

Effect of. Experimental Variables $\quad 17$

Response as a function of time after mixing. 18

$\mathrm{pH}$ dependence $\quad . \quad 20$

Effect of solvent 20

Survey of metals for response $\quad 25$

Determination of Cobalt 28

Description of the method 28

Inlerference study $\quad 33$

Analysis of samples $\quad 33$

Other Considerations 36

Simultaneous ultraviolet and chemiluminescent
detection

Observations . . 38

Elution of metals from a cation exchange resin $\quad 40$

SUMMARY AND CONCLUSIONS . 43

BIBLIOGRAPHY $\quad 44$

$\begin{array}{ll}\text { ACKNOWLEDGEMENTS } & 47\end{array}$ 
Chemiluminescent Detection of Metals

In Liquid Chromatography

Byron Malcolm Strom

Under the supervision of J. S. Fritz

From the Department of Chemistry

Iowa State University

A detector for liquid chromatography is described that uses the metal-catalyzed hydrogen peroxide oxidation of luminol (5-amino-2,3dihydro-1,4-phthalazinedione) to monitor metal ions in a column effluent. The effects of $\mathrm{pH}$, flow rate, distance of the flow cell from the point of mixing and the solvent type on the reaction of luminol are investigated. Several metals are surveyed for their ability to catalyze the luminol reaction. Cobalt(II), ruthenium(IV), gold(III), chromium(III) and copper (II) are found to be particularly effective catalysts.

A method for the separation of cobalt from nickel and chromium and a method for the subsequent determination of cobalt using chemiluminescent detection is reported. The results of the determination of cobalt in two National Bureau of Standards samples are shown. The calibration plot for cobalt is linear over a range of $0.4-100 \mathrm{ng}$.

*USAEC Report IS-T-638. This work was performed under contract W-7405-eng-82 with the Atomic Energy Commission. 


\section{INTRODUCTION}

Statement of the Problem

Since 1906, when the Russian botanist Tswett. first separated leaf pigments on a column of powdered calcium carbonate (1), chromatography has become a very powerful tool for the separation of a wide variety of closely related compounds, both organic and inorganic. The introduction of new resins of small particle size and the use of pressure to force solvents through a column packed with these fine resins has resulted in much faster and higher resolution separations. Thus, even very complicated mixtures such as body fluids have been separated into as many as 150 components within a few hours (2). Recently a chromatograph has been described that is resistant to attack by most mineral acids (3). This has made possible the use of high speed, high resolution liquid chromatography in the separation of metal ions.

With the capability of separating metal ions by high speed liquid chromatography came the problem of automatic detection of those ions. Most organic materials absorb light strongly in the ultraviolet region of the spectrum, making them easily detectable by uitraviolet spectrophotometry. However, most metal ions do not absorb light strongly in either the ultraviolet or vistble spectral regions. Other methods of chromatographic detection have been described for organic compounds (4), but most are not suitable for sensitive metal detection.

Ultraviolet detection has been applied to metals that form strongly ultraviolet absorbing chloride (2, 5, and 6) and bromide (7) complexes. Other materials have been determined photometrically by the in-stream 
addition of highly colored metal complexing agents $(8,9)$. Electroactive metals have been detected by recently developed coulometric techniques $(10,11)$. Alkali metals have been detected in a column effluent stream by atomic absorption spectrophotometry. (12) and the linear expansion of an ion exchange membrane (13). Detectors using thermal (14), refractive index (15) and conductivity (16) properties of the effluent have been used to monitor alkali metal salts.

One very sensitive technique for the determination of some metal ions is chemiluminescence, which has been defined as the emission of light in excess of black body radiation by a system undergoing a chemical reaction (17). Many chemical compounds are known to be chemiluminescent; among them luciferin in the firefly. Most of these compounds are weakly chemiluminescent and not useful for analytical purposes, but have been used in the study of reaction kinetics and mechanisms (18). Several reviews have recently been published on the chemiluminescence of a wide variety of compounds (19-21).

One of the most intense of the known chemiluminescent compounds is 5-amino-2,3-dihydro-1,4-phthalazinedione (Iumino1). During the basic oxidation of luminol a bright bluish light is emitted. This luminescence was first observed by Albrecht in 1928 (22). It occurs under a number of different oxidizing conditions, particularly in the presence of hydrogen peroxide and trace amounts of several metals. Russian workers have applied the metal catalyzed oxidation of luminol to the trace analysis of cobalt (23), copper $(24,25)$, iron $(26,27)$, manganese $(28)$, thorium (29), cerium (30), gold (31), mercury (32) and zirconium (33). They 
measured either the light produced by the metal catalyzed reaction, or the decrease in light of a copper catalyzed reaction upon the addition of another metal which quenches the copper luminescence.

The same reaction has been applied to the trace analysis of chromium (34) and iron (35) in natural waters at the subnanogram level. Table I summarizes some of the available information on the analytical applications of luminol to the determination of metal ions.

Because of the lack of sensitive, universal detectors for the liquid chromatography of metal ions, it has been necessary to rely on a variety of specific techniques that are suitable for one ion or a group of ions. Up to the present time the number of such techniques has been limited. Furthermore, the need for rapid, sensitive techniques for trace analysis is increasing, especially for monitoring environmental contaminants. The separating ability and speed of liquid chromatography alone are not sufficient to meet this need。

For these reasons it is important that promising new techniques be applied to liquid chromatographic detection. Chemiluminescence has sevcral advantages that make its application to liquid chromatography worthy of study. The metal catalyzed luminol reaction is sensitive. Detection limits for several metals have been measured in the parts per trillion range (36). The apparatus is simple. Unlike fluorescence measurements, chemiluminescent detection does not require a source of excitation radiation, nor does it require monochromators or filters. The flow cell is simple and inexpensive. The solvent change peaks normally observed in ultraviolet or visible detection do not occur, and 
Table I. Determination of metal ions using the chemiluminescence of luminol

\begin{tabular}{|c|c|c|c|c|c|c|c|}
\hline Metal & [Luminol] & {$\left[\mathrm{H}_{2}{ }^{0}{ }_{2}\right]$} & $\begin{array}{l}\text { Detection } \\
\text { limit }\end{array}$ & & $\mathrm{pH}^{\mathrm{i}}$ & Remarks & Ref. \\
\hline $\mathrm{Cu}(I I)$ & & & $30 \mathrm{ppb}$ & & 11 & & 24 \\
\hline $\operatorname{Co}(I I)$ & $4 \times 10^{-4}$ & $10^{-3}$ & 1 ng & & . & zinc matrix & 23 \\
\hline $\operatorname{Cr}($ III $)$ & $4 \times 10^{-4}$ & $10^{-2}$ & $25 \mathrm{pg}$ & & 10.8 & lake water & 34 \\
\hline$M n(I I)$ & $1 \times 10^{-3}$ & & $5 \mathrm{ppb}$ & & & activator & 28 \\
\hline $\mathrm{Fe}(\mathrm{III})$ & & & $10 \mathrm{ppb}$ & & 11.2 & activator & 27 \\
\hline $\mathrm{Fe}(\mathrm{II})$ & $4 \times 10^{-4}$ & none ${ }^{d}$ & $5 \mathrm{pg}$ & & $10.5-11.0$ & lake water & 35 \\
\hline $\operatorname{Zr}(\mathrm{IV})$ & $3 \times 10^{-4}$ & $6 \times 10^{-6}$ & $100 \cdot \mathrm{ng}$ & & $9.0-11.5$ & quenching $^{\mathbf{e}}$ & 33 \\
\hline $\operatorname{Th}(I V)$ & & & $2 \mathrm{ppm}$ & • & $9-11$ & quenching $^{\mathrm{e}}$ & 29 \\
\hline $\mathrm{Ce}(\mathrm{IV})$ & & & $20 \mathrm{ppm}$ & & 9 & quenching $^{e}$ & 30 \\
\hline $\mathrm{Hg}$ (II) & & & $200 \mathrm{ppb}$ & & 12.6 & & \\
\hline
\end{tabular}

${ }^{a}$ Value is the lower limit of the working range or the detection limit, when given.

b-10 Phenanthroline - citrate.

${ }^{\mathrm{Ac}} \mathrm{CH}_{2}$.

doxygen is the oxidizing agent.

e Determination by quenching of copper catalyzed chemiluminescence. 
bubbles in the system are not as serious as with ultraviolet detection because they are not easily trapped in the linear flow cell. Furthermore, the reagent tanks and mixing devices already in use for ultraviolet detection can be used for the necessary in-stream addition of reagents in chemiluminescence analysis.

This thesis will describe the modification of a present liquid chromatograph to meet the requirements of chemiluminescence analysis and will show the effects of several critical parameters on the detectability of some appropriate metal ions. Finally, a method for the determination of cobalt will be described and used in the analysis of synthetic and real samples.

The Luminol Reaction.

Luminol exhibits an intense blue luminescence when oxidized in a basic medium (22). The emission spectrum for the chemiluminescence. reaches its maximum intensity at $424 \mathrm{~mm}$ in aqueous solution and at 485 $\mathrm{nm}$. In dimethyl sulfoxide. The spectrum is identical with the fluorescence spectrum of the aminophthalate ion (37). In aprotic solvents.only oxygen and a strong base are needed for chemiluminescence; in protic solvents a base, an oxidizing agent and hydrogen peroxide are necessary. Certain transition metal ions in the presence of hydgrogen peroxide can be substituted for the oxidizing agent in protic solvents (19). It is the property of transftion metals to catalyze the chemiluminescent oxidation of luminol in the presence of base and hydrogen peroxide that makes the system useful for the trace analysis of these metals. 
Several mechanisms have been described for the chemiluminescent reactions of luminol in various media $(17,38,39)$. These mechanisms in general involve the removal of a hydrazide hydrogen and a series of oxidation steps resulting in the formation of the aminophtalate ion in an excited state. Figure 1 shows this overall mechanism. Light characteristic of the aminophthalate ion is emitted when it returns to its ground state. In the case of luminol oxidation in protic solvents, hydrogen peroxide free radicals produced by the interaction of a metal ion and the peroxide are thought to be involved in the oxidation steps (19). The reasons that some metals act as catalysts for the chemiluminescent oxidation of luminol in the presence of hydrogen peroxide and base are not readily apparent. Metal catalysts for peroxide decomposition are of two general types: homogeneous catalysts, which exert a catalytic effect while in true molecular solution; and heterogeneous catalysts, which become catalytic as they precipitate. It seems to be the heterogeneous catalysts which operate in the oxidation of luminol. Babko and Lukovskaya (40) has stated that the cobalt species which is responsible for catalyzing the luminol oxidation is really cobalt(III) hydroxide.

Table II shows a summary of metals that have been observed to catalyze the decomposition of hydrogen peroxide. The heterogeneous catalysts are noted. A comparison with Table III, which shows metals that have been analytically determined using the luminol-peroxide reaction, suggests that the heterogeneous catalysis of hydrogen peroxide decomposition by metals and the ability to produce chemiluminescence in the luminol reaction are indeed closely related. 


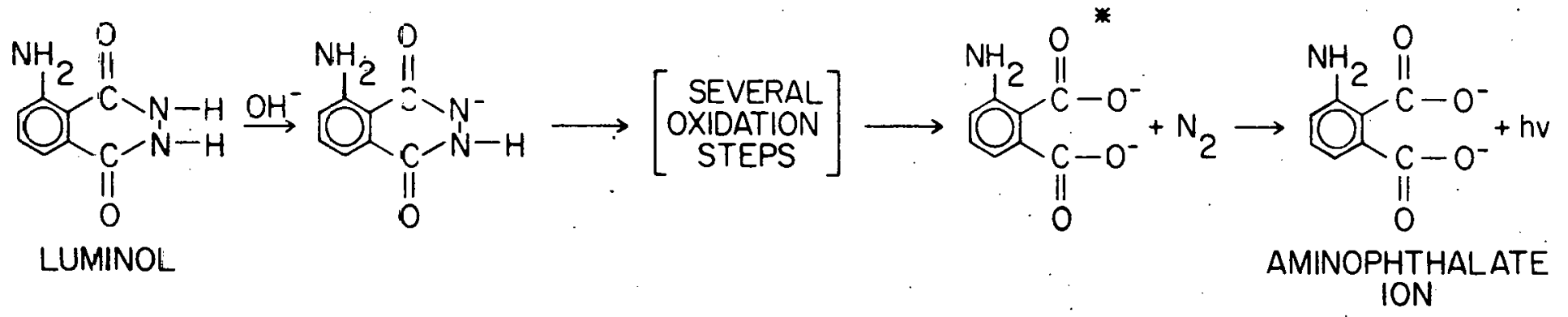

Figure 1. Overall mechanism of the luminol reaction 
Table II. Catalysis of hydrogen peroxide decomposition ${ }^{a}$

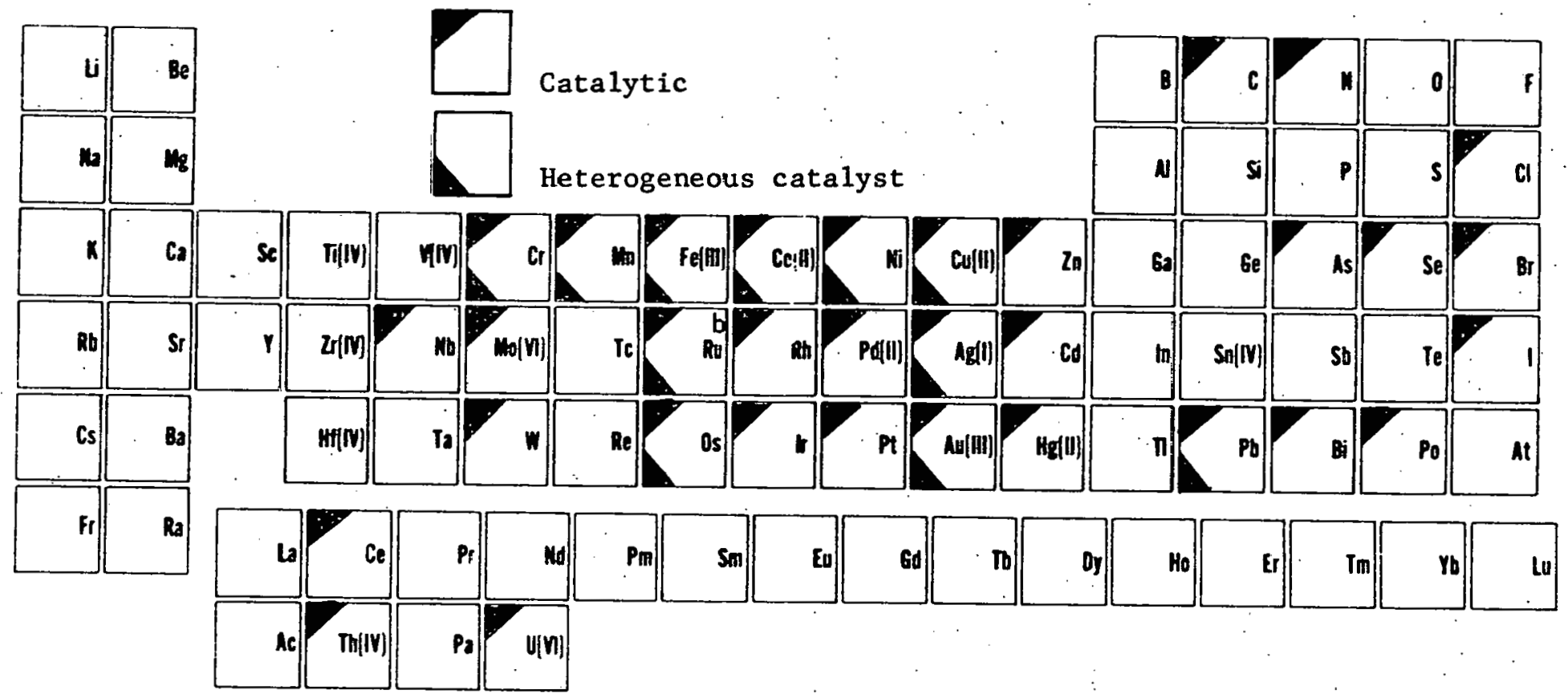

${ }^{a}$ Schumb et a1., (41, p. 467-501).

${ }^{b}$ Dwyer et al., (42, p. 138$)$. 
Table III. Metals determined using the metal-catalyzed hydrogen peroxide oxidation of luminol ${ }^{a}$

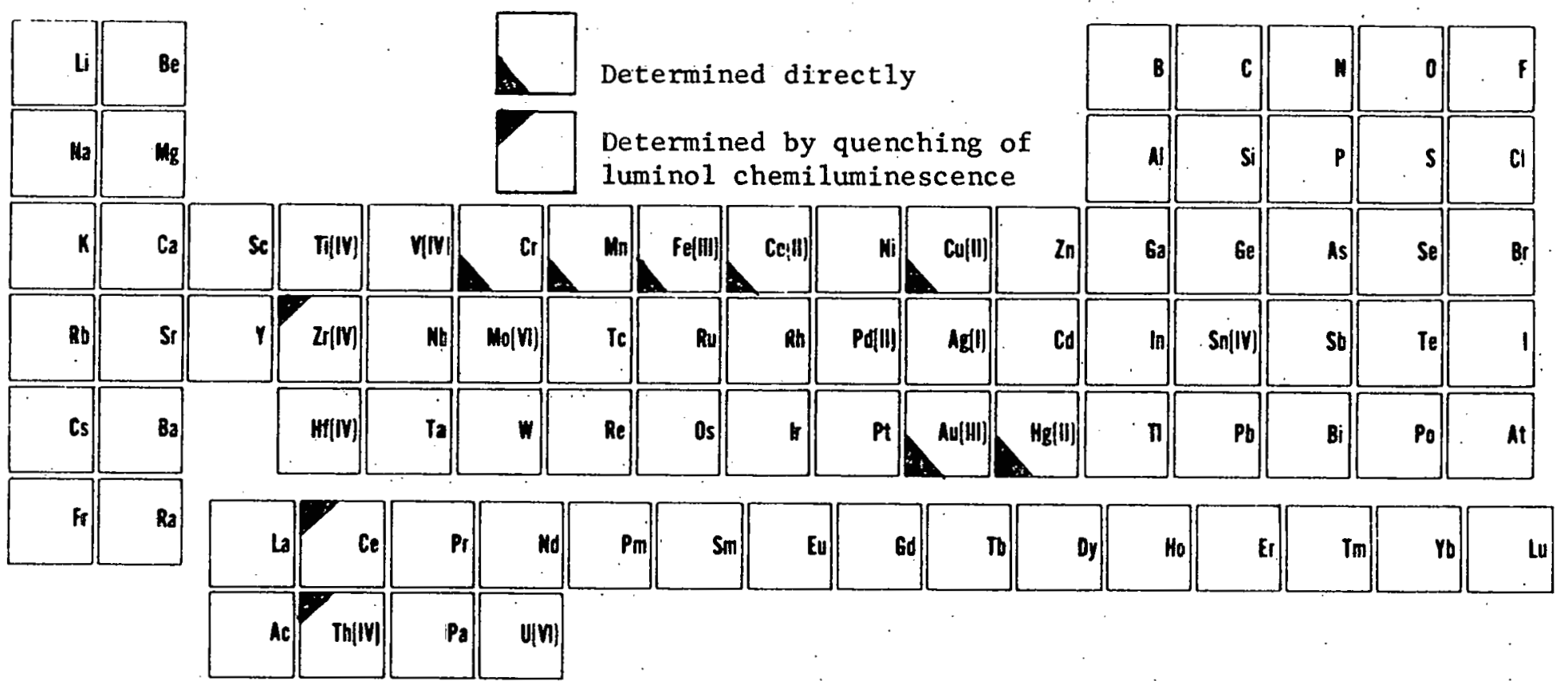




\section{EXPERIMENTAL}

Apparatus

\section{Chromatograph}

The eluent delivery system used in this work is essentially the same as that described by Seymour et al. (5). A diagram of the present chromatograph is shown in Figure 2. The signal readout system consists of an RCA 1 P28 photomultiplier tube within a light-tight housing, a Heath EU-703-31 Photometric Readout Module and a one-volt Heath EU205-11 Strip Chart Recorder. Two of the reagent tanks are used to hold the light-producing reagents; a dilute hydrogen peroxide solution is contained in one and the buffered luminol solution in the other. The remaining tanks hold eluents appropriate for the particular column separations being done. In order to adjust the relative flow rates of the eluent stream and the light-producing reagents, 0.012-in. i.d. Teflon tubing is used. Throughout the remainder of this thesis the term "resistance tubing" will be used to designate the 0.012-in. Teflon tubing. Usually the resistance tubing after the column is kept constant and only the resistance tubing in the buffer stream is varied.

In normal operation helium pressure ranging from about 10-25 psi is applied equally to all tanks. The buffered luminol mixes in a tee with hydrogen peroxidc, and that mixture combines with the column effluent in a mixing chamber. The mixing chamber is of a whirlpool, divided tangential entry type described by Sickafoose (43). The eluent flow rate is measured by means of a calibrated flow meter ahead of the column, while the total flow rate through the detector is measured with 


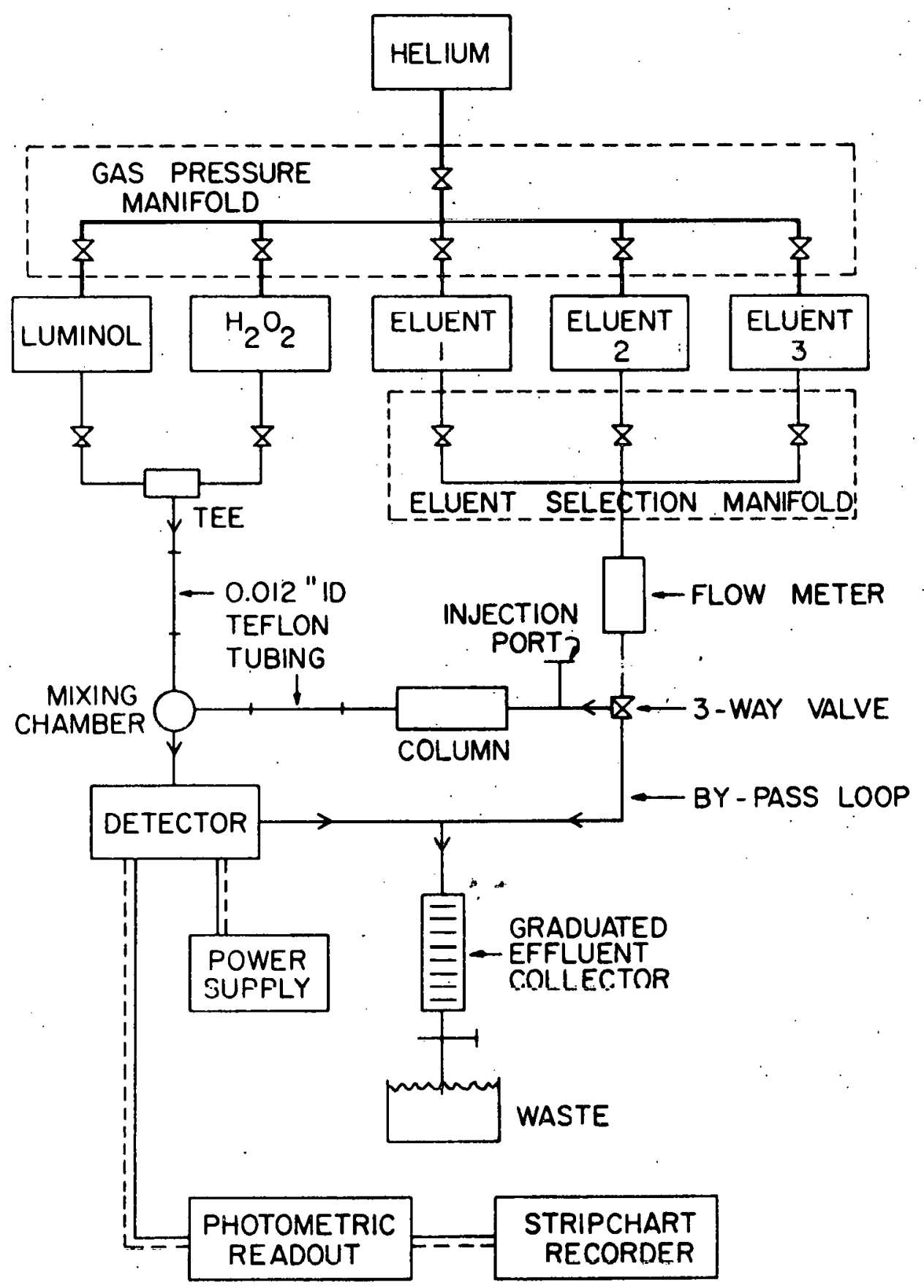

Figure 2. Diagram of chromatographic system 
the graduated effluent collector and a timing device.

Materials used in the chromatograph are resistant to attack by most corrosive solutions. All tubing except the resistance tubing is 0.031 in. i.d. Teflon. The tee, mixing chamber, eluent valves and injection port are machined from Kel-F. The column and flow cell are glass.

\section{Detector}

Photomultiplier tube housing A light-tight steel utility cabinet, $4 \times 5 \times 6$ in, is used to house the detection assembly. An RCA 1 P28 photomultiplier tube is secured to the cabinet in an 11-pin socket mounted on a metal platform. The photomultiplier tube assembly wiring diagram is shown in Figure 3. Power is supplied to the photomultiplier tube by means of banana plugs from the external high voltage output of the Heath EU-701-30 Photomultiplier Module. Normal operating voltage is 600 volts. The signal is carried to the photometric readout module by means of a shielded cable with BNC connections. The inside of the utility cabinet was painted with a flat black enamel spray paint. The cabinet is so constructed that two sides can easily be removed for installation of the photomultiplier tube and flow cell. Aplezon Wax $W$ was used to seal the corners and edges of the box.

Flow cel1 A 6.6-mm o.d. glass capillary tube with a 1-mm i.d. bore is used for the flow cell. The capillary tubing was bent about one Inch from the end as shown in Flgure 4 so that the tube could rest flush against the face of the photomultiplier tube. Kel-F couplings which could take Chromatronix tube-end fittings were attached to the capillary tube. The tube was masked with black electrical tape so that 


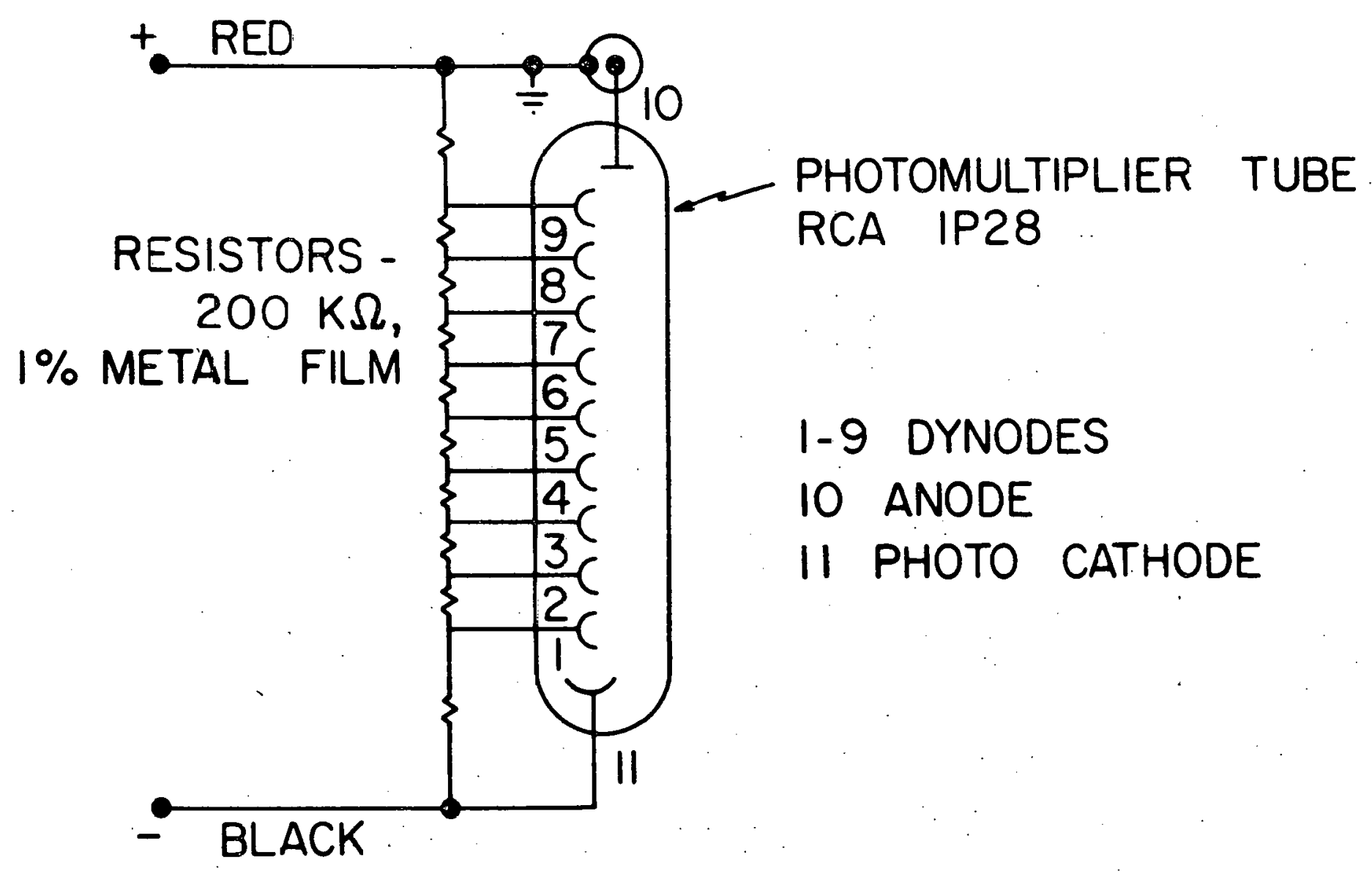

Figure 3. Photomu1tiplier tube assembly wiring diagram 


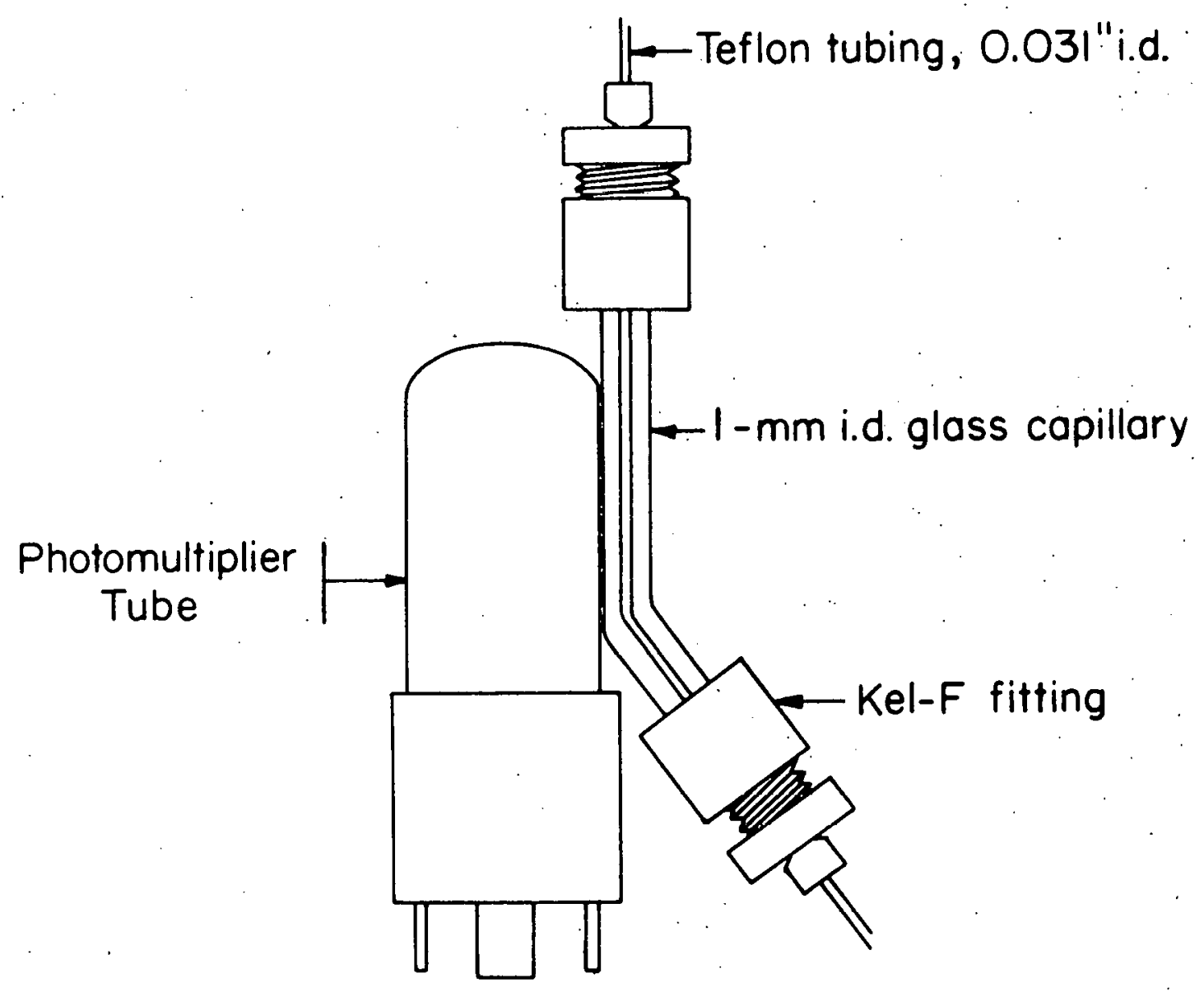

Figure 4. Position of the flow cell with respect to the photomultiplier tube 
only one inch of tubing adjacent to the light-sensitive window of the photomultiplier tube was transparent. The volume of this portion of the flow cell is $21.8 \mu 1$. The flow cell is held against the photomultiplier tube with masking tape: Aluminum foil is placed between. the tape and the flow cell.

\section{$\underline{\text { Column }}$}

A 6.3-mm i.d. Chromatronix model LC-6M-13 analytical column is used.

\section{Reagents}

All solutions were prepared from reagent grade chemicals in distilled water deionized with an IWT Research Model II Ion Exchanger. Luminol-buffer solution

Luminol was obtained from Aldrich Chemical Company and was used as received. Normally two liters of the luminol-buffer solution were prepared. The solution contained $4 \times 10^{-4} \underline{M}$ luminol and varying amounts of potassium hydroxide and sodium borate depending on the acidity and flow rate of the eluent stream and the desired final $\mathrm{pH}$.

\section{Hydrogen peroxide}

A dilute hydrogen peroxide solution was prepared by the addition of $1 \mathrm{~m} 1$ of $30 \%$ hydrogen peroxide to two liters of water. This resulted in a solution approximately $0.005 \underline{M}$ in hydrogen peroxide. Narmally the solution was freshly prepared at the beginning of a run and retained its activity over a period of at least three days. However, no attempt was made to determine long range stability of the solution because of the 
difficulty of reproducing flow and $\mathrm{pH}$ conditions exactly, and because of the ease of preparation of the reagent.

\section{Methanol-hydrochloric acid solutions}

To prepare a $70 \%$ methanol-0.6M HCl solution, $1400 \mathrm{ml}$ of absolute methanol was measured in a two liter graduated cylinder, $100 \mathrm{ml}$ of concentrated hydrocloric acid was added and the volume was made up to two liter mark with water. This pattern was followed in the preparation of all the methanol-hydrochloric acid solutions. 


\section{RESULTS AND DISCUSSION \\ Effect of Experimental Variables}

The factors that affect the intensity of a signal for a given metal in the luminol-peroxide system include the following: the $\mathrm{pH}$ of the chemilumingescent mixture, the presence of inhibitors, activators and complexing agents, and the rate of the reaction. In a flowing system where mixing takes place the relative flow rates of the eluent and the light-producing reagents determine the $\mathrm{pH}$ of the reaction. The total flow rate and the rate of reaction determine the position of optimum light intensity downstream from the point of mixing. Thus the experimental variables that can be manipulated once a particular metal and eluent have been chosen are the helium pressure applied to the eluent and lightproducing reagent tanks, the resistance in the column stream and the resistance and $\mathrm{pH}$ in the light reagent stream. The effect of temperature was not taken into account. In studies of cobalt in the luminol-hydrogen peroxide system, Babko and Lukovskaya (44) state that the temperature effect is small.

A length of tubing was used in place of a column in these experiments except where stated otherwise. The "eluent" was $0.1 \mathrm{M}$ hydrochloric acid. The $\mathrm{pH}$ was adjusted by varying the length of resistance Lubing in the light reagent and/or column streams and, where necessary, by changing the basic1ty of the luminol-borate with potassium hydroxide. Generally, the column stream resistance was held constant and the light reagent stream resistance was varied. The solution passing out of the 
detector was collected, and its $\mathrm{pH}$ was taken to be that of the reaction. A11 injections were $51.4 \mu 1$.

\section{Response as a function of time after mixing}

Cobalt(II), chromium(III), copper(II) and iron(III) were studied to observe the effect of the time after mixing on the signal intensity. The flow rate through the detector was maintained at a nearly constant value. The length of tubing between the mixing chamber and the detector was varied. The volume of the tubing was calculated assuming a constant diameter of 0.031 in. (the stated diameter) and the time required for the solution to pass through this volume was plotted versus the intensity of the detector signal. The $\mathrm{pH}$ during the course of these measurements varied between 11.1 and 11.3 .

The results of these experiments are shown in Figure 5. The cobalt. (II) and iron(III) responses are fairly fast, reaching a maximum intensity in less than $1 \mathrm{sec}$. In these cases the intensity returns quickly to a low level. Chromium(III) shows a some what slower response while copper(II) reaches a maximum intensity only after about 5 sec. and appears to tail off slowly. These data indicate that it should be possible to reduce an interference or enhance a desired response by a judicious choice of the flow rate and of the length of tubing placed after the mixing chamber.

Babko and Lukovskaya (45) support thesc data qualitatively. They found that kinetic curves for the luminol-peroxide reaction reach a maximum for cobalt at $1 \mathrm{sec}$. and for copper at $3 \mathrm{sec}$. 


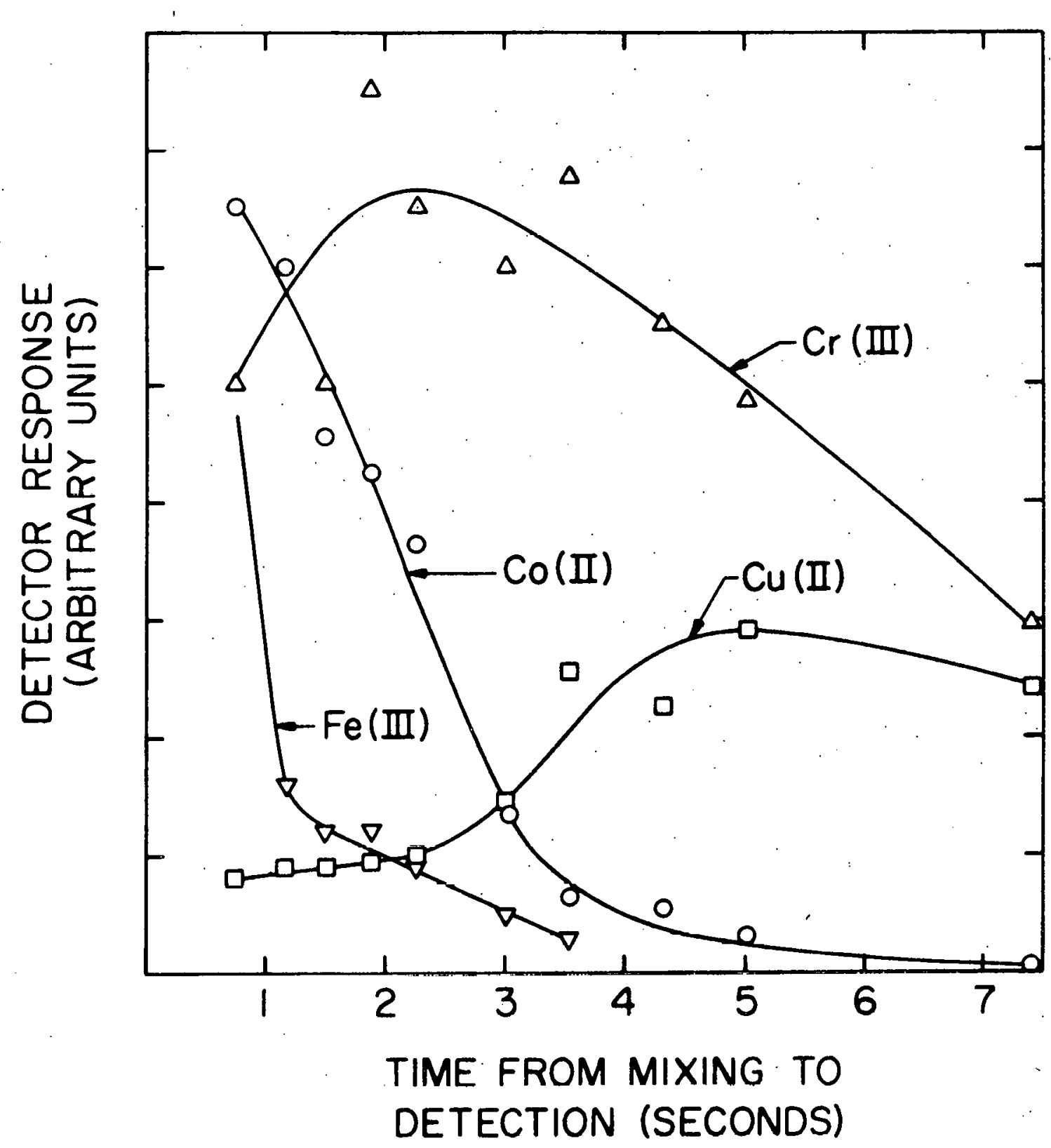

Figure 5. Effect of time from mixing to detection on the intensity of chemiluminescence catalyzed by 10 ppb cobalt(II), 1 ppm chromium(III), $1 \mathrm{ppm}$ iron(III) and 1 ppm copper(II) 
The widely-scattered values for chromium(III) have not been explained. A variation in $\mathrm{pH}$ upon changing the tubing could cause this behavior, but the $\mathrm{pH}$ at a given tubing length was. the same for all the metals studied.

$\mathrm{pH}$ dependence

The $\mathrm{pH}$ dependence of the intensity of chemiluminescence catalyzed by several metals was measured. The $\mathrm{pH}$ was varied by the addition of potassium hydroxide pellets to the luminol-borate solution, and the solution was thoroughly mixed after each addition. For each addition only the gas pressure manifold valve of the tank containing the lumino1borate mixture was shut off. The helium regulator valve remained untouched and the pressure on the tanks remained constant when the gas valve to the luminol-borate tank was reopened.

Figure 6 shows the results of this experiment. The optimum $\mathrm{pH}$ for most of the metals tested is above 10.5. However, iron(II) and iron(III) show maxima between 9.0 and 9.5. Manganese(II) (not shown) gave a negative response in the $\mathrm{pH}$ range 10.5 to 11.0 . Evidently manganese acts to suppress the background chemiluminescence of metals present in the reagents. In order to catalyze the luminol reaction, manganese must be in the presence of an activator (28).

\section{Effect of solvent}

Figures 7-9 show the effect of varying concentrations of methanol, acetone, acetonitrile and 2-propanol on the chemiluminescence catalyzed by cobalt, copper and chromium. In each case the metal was injected into a stream of the solvent made up in $0.1 \mathrm{M}$ hydrochlol acid.

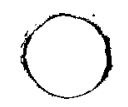



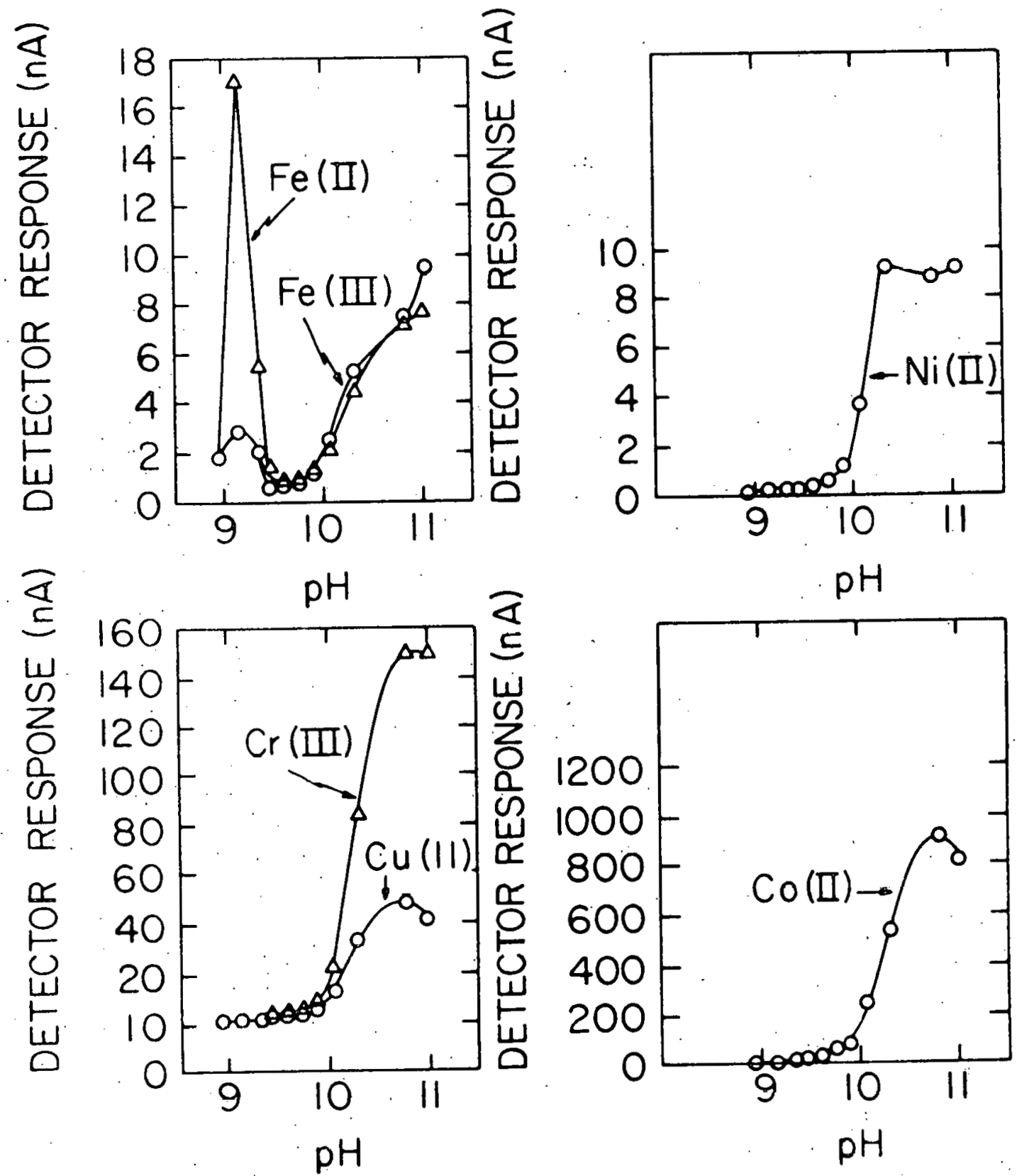

Figure 6. pH dependence of chemiluminescence catalyzed by several metals (concentration of injected metals: cobalt $10 \mathrm{ppb}$, and others $1 \mathrm{ppm}$ ) 


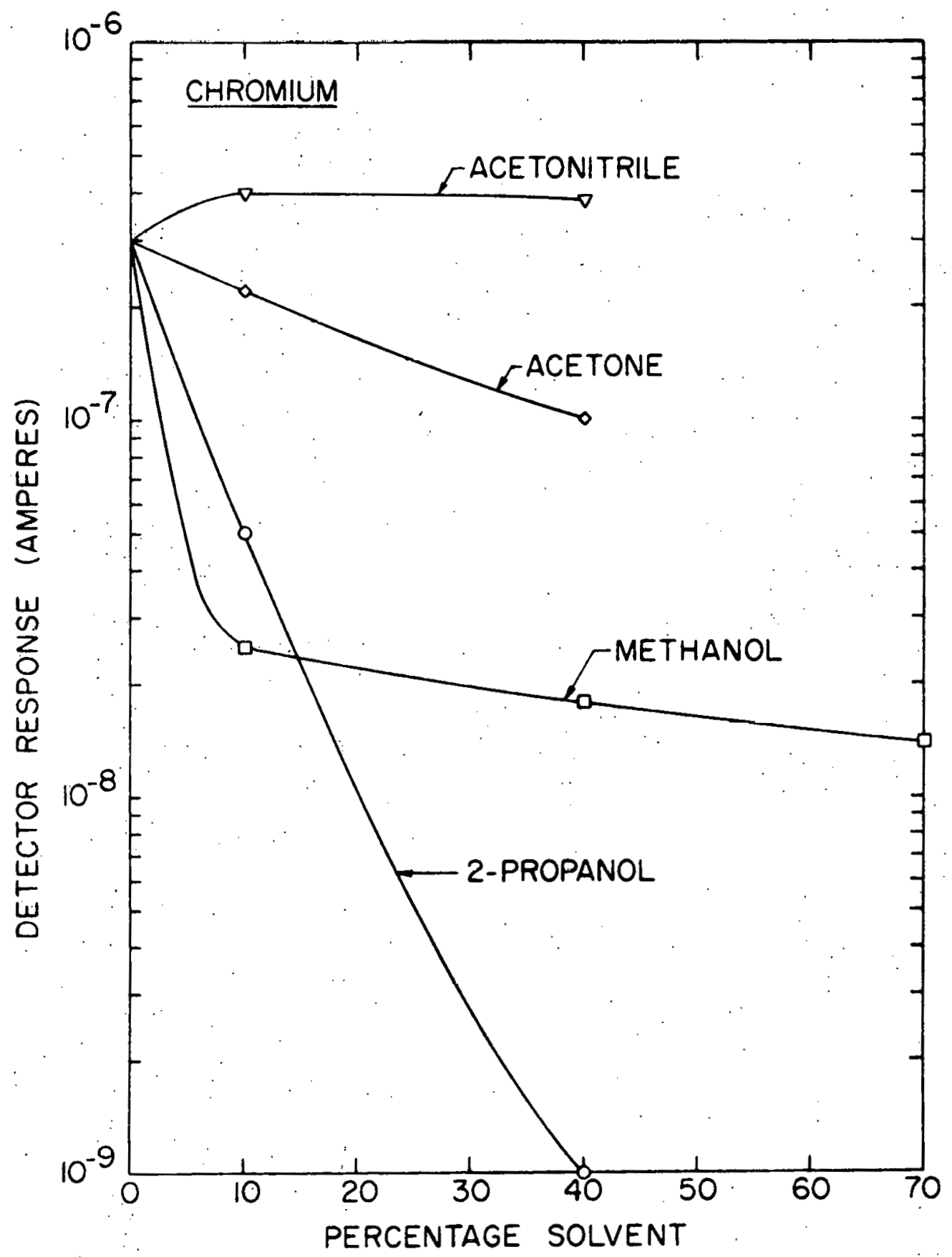

Figure 7. Effect of organic solvents on the chemiluminescence catalyzed by $100 \mathrm{ppm}$ chromium(III) 


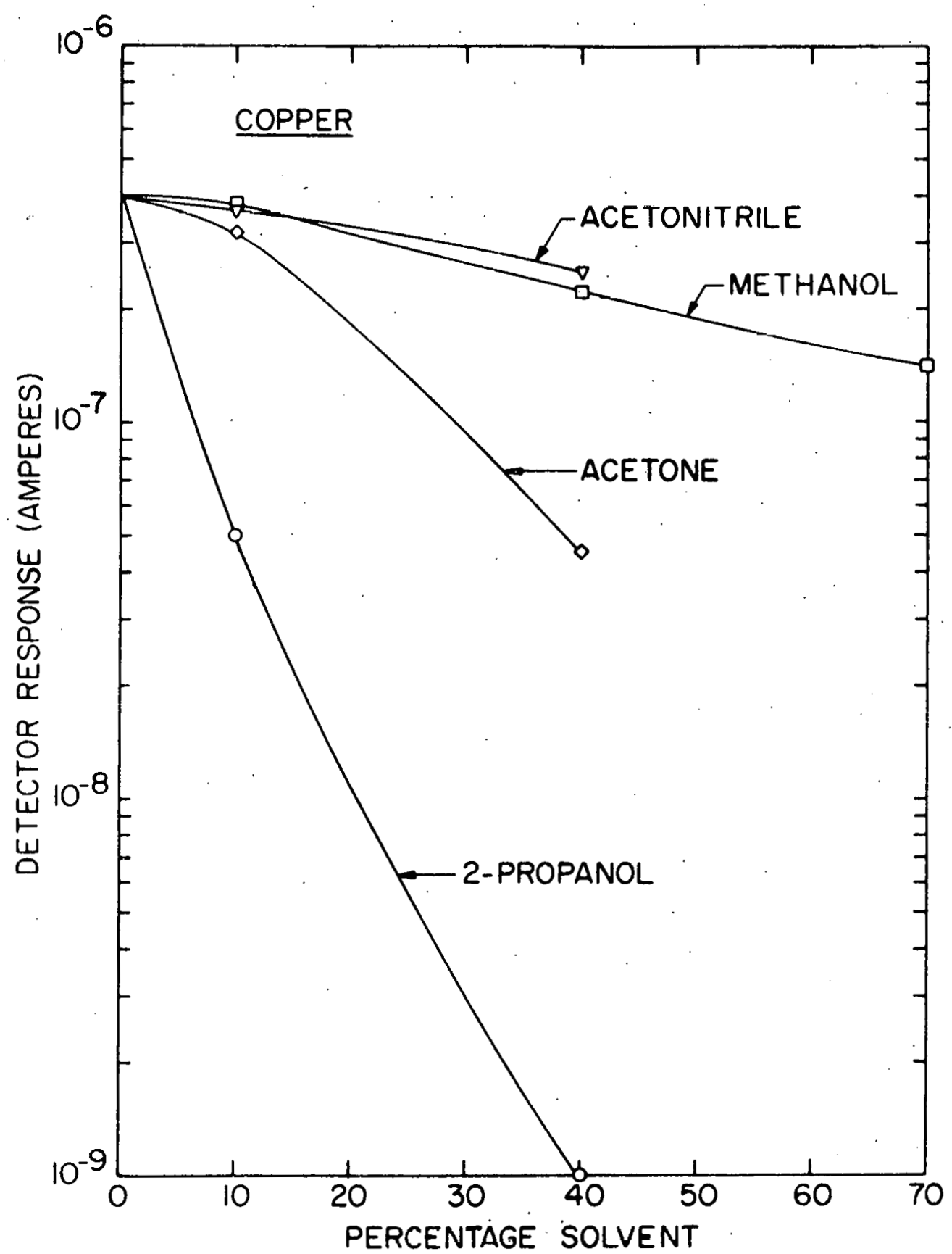

Figure 8. Effect of organic solvents on the chemiluminescence catalyzed by $100 \mathrm{ppm}$ copper(II) 


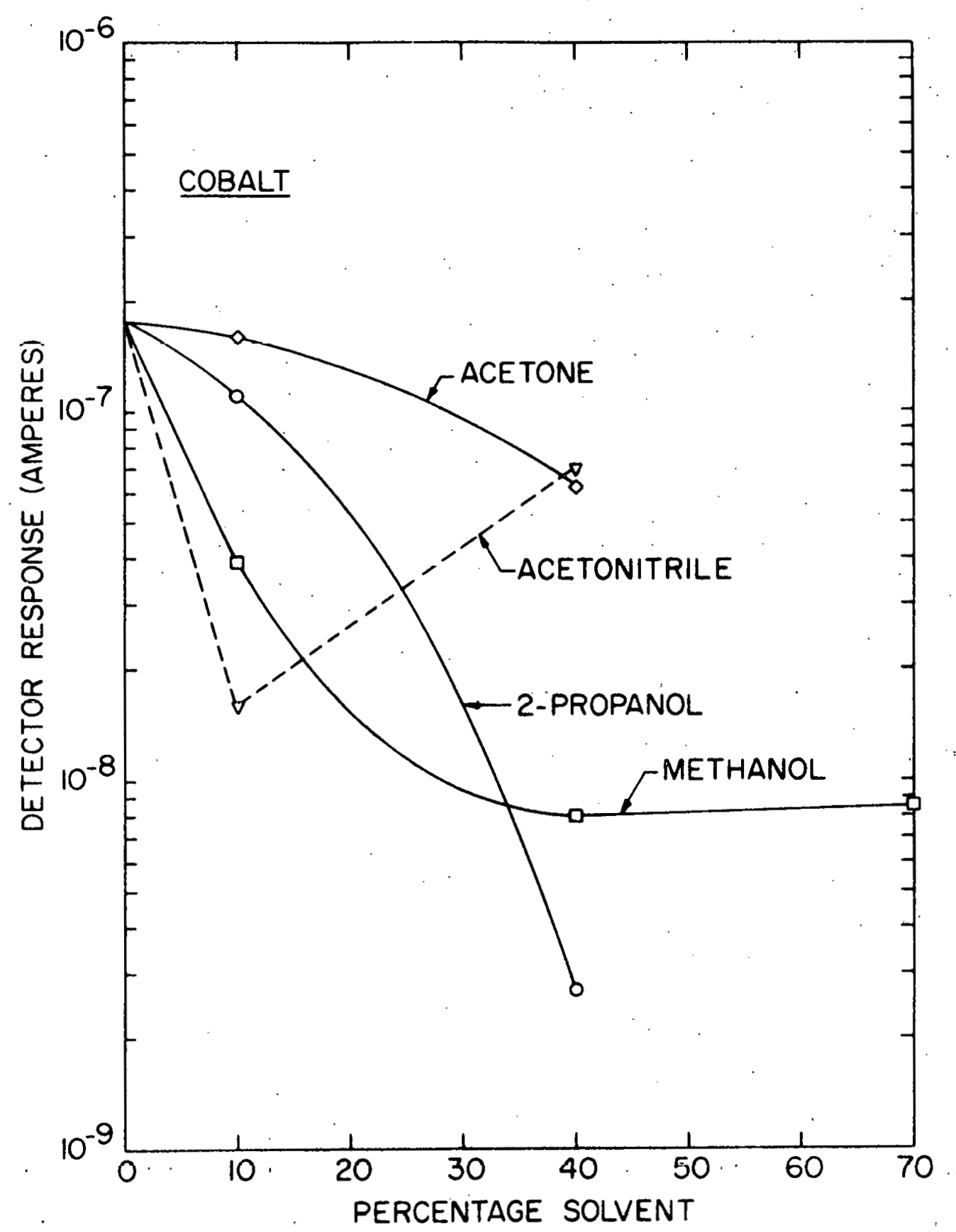

Figure 9. Effect of organic solvents on the chemiluminescence catalyzed by $10 \mathrm{ppb}$ cobalt(II) 
Precipitation of the borate buffer occurred when $70 \%$ acetonitrile and $70 \%$ acetone were used, blocking the tubing in the chromatographic system. of the four solvents, 2-propanol gives the least response for the metals tested.

Acetonitrile and acetone generally affect the signal least, with the exception of cobalt in $10 \%$ acetonitrile and copper in methanol. l'he signal in methanol is reduced to a much greater extent for cobalt and chromium than it is for copper. The approximate amounts of metal ions injected were $0.5 \mathrm{ng}$ cobalt(II), $5 \mu \mathrm{g}$, chromium(III) and $5 \mu \mathrm{g}$ copper (II).

\section{Survey of metals for response}

In the initial work on this problem a number of metals were surveyed for their catalytic effect on the intensity of the light emitted by luminol. The detector response was noted after the metal in question was injected into a stream of $0: 1 \mathrm{M}$ hydrochloric acid.

In this first survey optimum conditions of $\mathrm{pH}$ and of the time from mixing to detection were not used. The metals thus surveyed included rhenium(IV), cerium(III), silver(I), cobalt(II), ruthenium(IV), aluminum(III), gallium(III), palladium(II), germanium(IV), indium(III), vandium(IV), gold(III), platinum(IV), potassium(I), berylium(II), lithium(I), strontium(II), tin(IV), mercury(II), europium(III), calcium (II), thorium(IV); cadmium(II), manganese(II), nicke1(II), magnesium(II), zinc(II), copper(II), lead(II), iron(III) and chromium(III). These solutions had been previously prepared by Mark Seymour. Several metals 
that in the initial survey appeared to have promise as sensitive catalysts for luminol oxidation were re-surveyed.

Metal salts were dissolved in $0.1 \mathrm{M}$ hydrochloric acid and diluted to approximately $1 \mathrm{ppm}$ in that acid, with the exception of silver nitrate, which was dissolved and diluted in 0.1M nitric acid. The luminol solution was $0.1 \mathrm{M}$ in sodium borate. The $\mathrm{pH}$ was varied in the manner described in the $\mathrm{pH}$ dependence section of this thesis. The total flow rate remained at $8.0 \mathrm{ml} / \mathrm{min}$. throughout the experiment. Provision was made for rapidly changing the length of the tubing after the mixing chamber by means of a three-way valve which routed the solvent stream through either a 2-in. or a 22-in. length of tubing. In this way a metal whose signal went off scale could be monitored at a less sensitive point in its intensity versus time curve.

Table IV shows the results of this experiment. The light intensity reaches a maximum for all metals between $\mathrm{pH} 10.1$ and 12.2 , with the possible exception of ruthenium. Those metals giving a signal significantiy larger than that of the $0.1 M$ hydrochloric acid itself include coba1t (II), ruthenium(IV), chromium(III), gold(III), copper(II), mercury(II), silver(I), iron(II), manganese(II) and iron(III). It is not known why manganese(II) did not give a negative response here as it has in other work (see $\mathrm{pH}$ dependence section, this thesis). Ruthenium(IV) is an effective catalyst, as well as gold(III). It is likely that others of the platinum metals may also exhibit strong catalysis (see Table II), although in the preliminary survey platinum itself did not. The copper response was surprisingly low based on 
Table IV. Chemiluminescent activity catalyzed by metals (detector response X $10^{9}$ amperes)

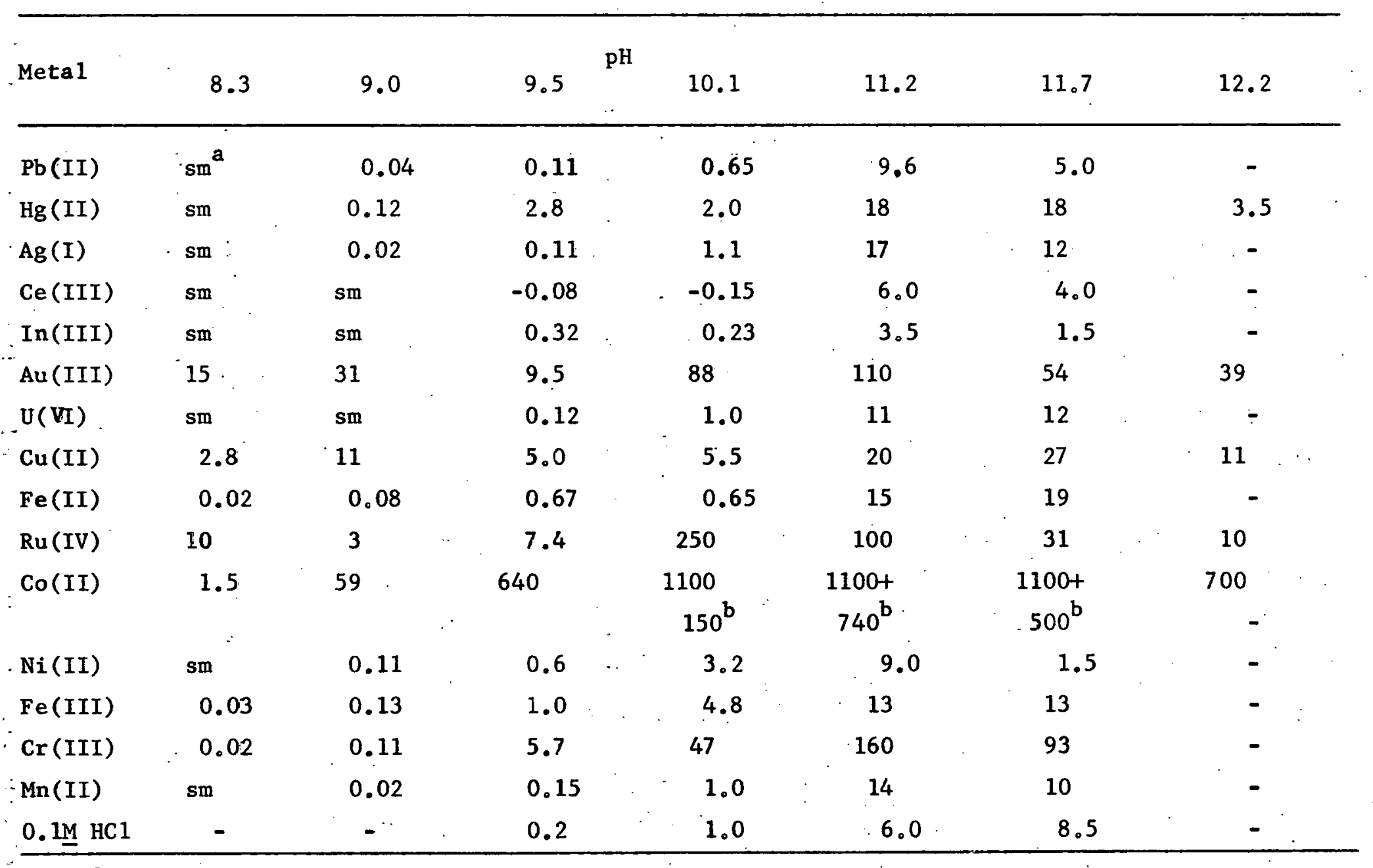

$a_{\text {sm }}$ indicates that the response was indistinguishable from the background noise.

${ }^{b}$ Response using a longer tubing length after the mixing chamber. 
earlier work (Figure 6) and on references to the sensitivity of copper catalysis (36). It is clear that cobalt catlayzes the luminol reaction to the greatest extent.

In the interpretation of data of this type it must be remembered that the presence of a sensitive catalyst impurity in another metal salt could give rise to an erroneously high response for that metal salt. Thus, the metals exhibiting a low but measurable signal must be regarded as suspect.

\section{Determination of Cobalt}

Description of the method

Because of the particular sensitivity of cobalt in the hydrogen peroxide-luminol system, it was decided to develop a chromatographic method for cobalt using luminol-peroxide as the detector: In any chromatographic method for one element it is desirable to find conditions such that the element to be determined is retained on a column, while at the same time interfering elements are not held. The retained element is then removed in a tight band and determined. Copper, iron and nickel have been reported to interfere with the chemiluminescent determination of cobalt (44). Furthermore, it would seem desirable to separate cobalt from chromium, which has been shown to be a sensitive catalyst, and from manganese, which inhibits the cobalt signal.

A problem that arises in the application of chemiluminescent detection to chromatographic metal separations is the relatively narrow range of $\mathrm{pH}$ that will allow the luminol reaction to occur. Thus, it is desirable to use an eluent with as low a hydronium ion concentration as 
possible. The anion-exchange separation of the transition metals from cobalt, using the hydrochloric acid scheme $(46)$, requires $5-6 \mathrm{M}$ hydrochloric acid to sorb cobalt as an anionic chloride complex.

In order to reduce the hydronium ion concentration and still maintain conditions for the formation of anionic chloride complexes of cobalt, it is necessary to use chloride salts and/or organic solvents. Seitz and Hercules (47) report the use of a concentrated lithium chloride solution for the separation of cobalt, nickel and copper using chemiluminescent detection. It has been found that a solution $0.6 \mathrm{M}$ in hydrochloric acid can be used in conjunction with methanol satisfactorily, providing that the buffer strength and relative flow rates of the lightproducing reagents and eluent are adjusted properly.

Several metal ions including cobalt, iron and copper are sorbed to Dowex 1 in 95\% methano1 - 0.6M hydrochloric acid, but nickel, chromium and manganese are not (48). Cobalt is then quickly stripped from this resin in $70 \%$ methano $1-0.6 \mathrm{M}$ hydrochloric acid. Copper and iron are eluted more slowly. A complete separation of cobalt from copper and iron was not accomplished under these conditions in any reasonable length of time suitable for an analysis.

The resin used was 200-400 mesh Bio-Rad AG 1-X4. Th1s resin is a purifted version of Dowex 1. A resin with spherical beads was chosen to reduce the posslbilities of flow varlation caused by column clogging. Seymour. (49) has reported that even with careful treatment resins that have been ground and seived show a tendency to clog. The column length was $4.2 \mathrm{~cm}$, the diameter $6.3 \mathrm{~mm}$ and the resin weight $0.74 \mathrm{~g}$. The Iuminol- 
borate solution used in the determination of cobalt contained $0.4 \mathrm{M}$ sodium borate and approximately 0.9 Motassium hydroxide.

The column is first pre-equilibrated by running $0.6 \mathrm{M}$ hydrochloric acid through it for several minutes to remove any metal ions still remaining on the column. Then the eluents used are run alternately. through the column several times. During this pre-equilibration the helium regulator valve is adjusted so that it shows a pressure of twenty pounds.

The run is begun by allowing the sorbing medium, $95 \%$ methanoi $-0.6 \mathrm{M}$ hydrochloric acid, to pass through the column for 3 to $4 \mathrm{~min}$. A $51.4 \mu \mathrm{I}$ cobalt sample made up in the sorbing medium is then injected onto the column. After 2.4 min; the eluent is changed to $70 \%$ methanol $-0.6 \underline{M}$ hydrochloric acid and the cobalt peak is observed. A typical cobalt peak is shown in Figure 10. After $3 \mathrm{~min}$, $95 \%$ methanol - $0.6 \underline{M}$ hydrochloric is again passed through the column for $3.6 \mathrm{~min}$, when a new injection can be made. The chart speed is normally $6 \mathrm{~min} / \mathrm{in}$. The flow rate for the $70 \%$ methanol - $0.6 \mathrm{M}$ hydrochloric acid eluent in this elution sequence is $0.8 \mathrm{ml} / \mathrm{min}$. and the total flow rate is $12.0 \mathrm{ml} / \mathrm{min}$. Figure 11 shows a calibration plot for cobalt using this elution sequence. (The elution sequence time intervals were dictated by the chart speed and chart markings as we11 as hy the time for elution of metal ions,)

During the run, the eluent flow was monitored each time the eluent was changed. This was necessary to detect variations in flow that could render runs useless. In general, during the course of 3-to 4-hour run the flow rate gradually decreased. This decrease leveled out with time, 


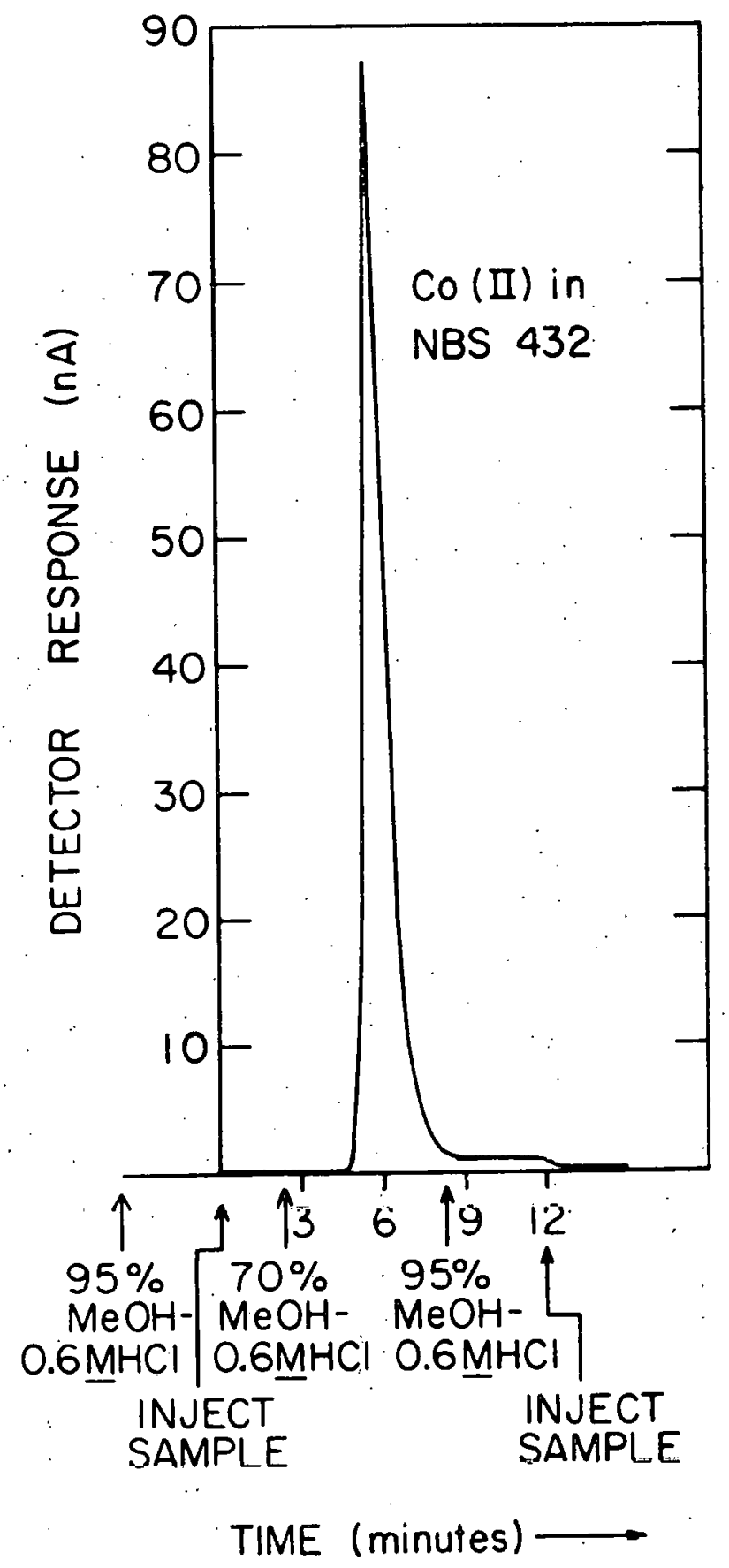

Figure 10. Typical cobalt peak (35 ng) 


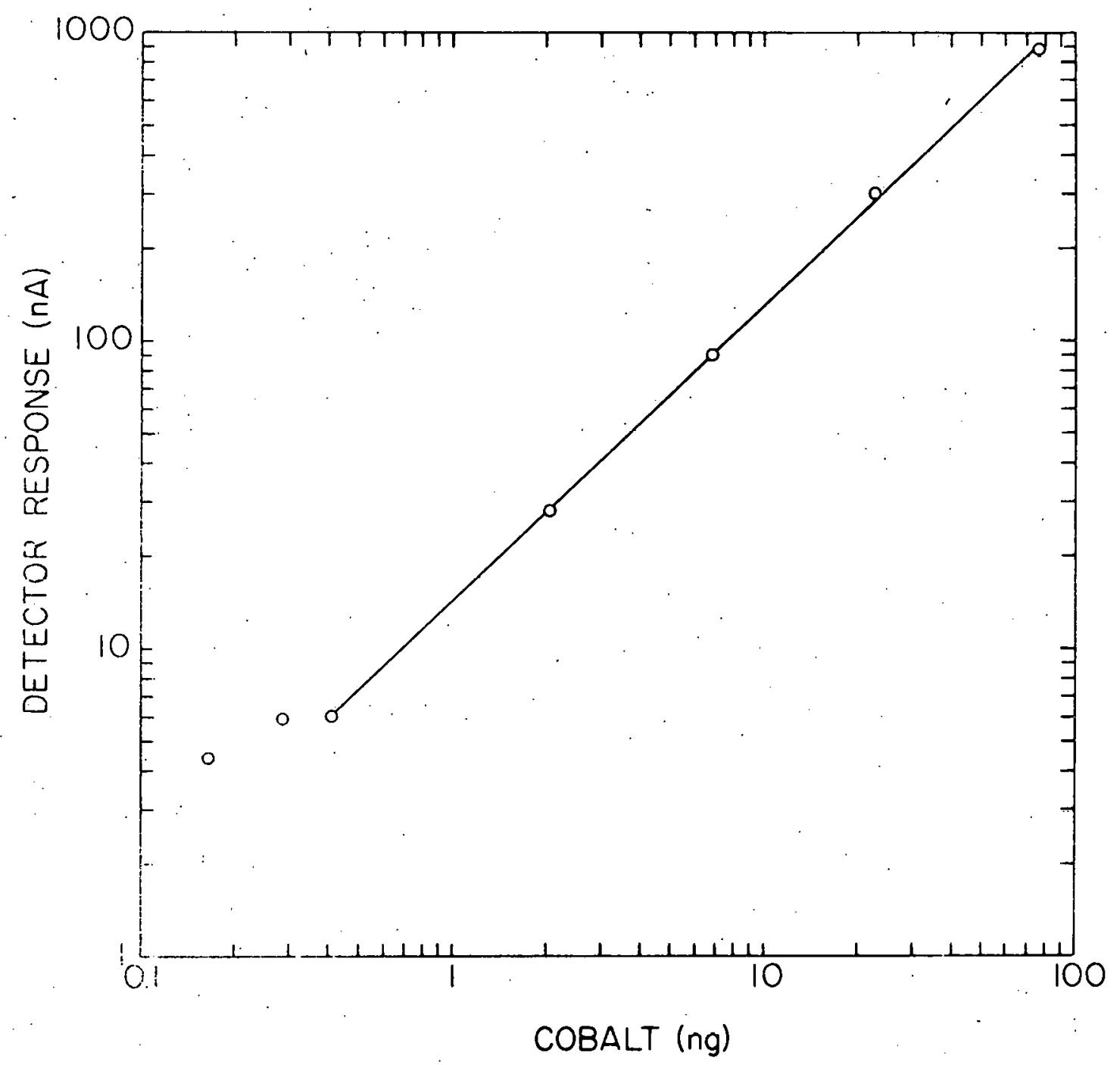

Figure. 11. Calibration plot for cobalt peak height 
but it was occasionally necessary to readjust the regulator valve.

Interference study

Table $\mathrm{V}$ shows the results of the interference study. The elution sequence for the cobalt determination was used. The values in the table represent single injections of solution containing cobalt and the potentially interfering metal ion.

of the metal ions studied, nickel(II) shows the least interference. Chromium(III), copper(II) and iron(III) interfere to some extent at large metal-to-cobalt ratios. In these cases the signal is greater than the expected for cobalt alone, probably because light is emitted due to the presence of these ions. However, the cobalt signal with manganese(II) is severely depressed, indicating some type of interaction between manganese and the catalytic form of the cobalt, the luminol, or one of the intermediates in the luminol reaction. This interference would probably be reduced by using a longer sorption step, thereby allowing the manganese to completely wash from the column before cobalt is eluted. Analysis of samples

The results of the andyses of three samples for cobalt are shown in Table VI. A synthetic sample containing $200 \mathrm{ppm}$ chromium(III) and nickel(II), and $0.3 \mathrm{ppm}$ cobalt(II) was prepared in $95 \%$ methanol $-0.6 \mathrm{M}$ hydrochloric acid and analyzed for cobalt. NBS-432, a tin base alloy, was dissolved in a mixture of nitric and hydrochloric acids and taken up in $100 \mathrm{ml}$ of the sorbing medium to give a concentration of cobalt within the range of a standard calibration plot. NBS-169, an electrical 
Table $V$. Interferences in the determination of cobalt

\begin{tabular}{ccccc}
\hline Interference & $\frac{\text { ng metal }}{\mathrm{ng} \text { cobalt }}$ & $\begin{array}{c}\text { Cobalt } \\
\text { added (ng) }\end{array}$ & $\begin{array}{c}\text { Cobalt } \\
\text { found (ng) }\end{array}$ & \%Error \\
\hline $\mathrm{Ni}(\mathrm{II})$ & 67 & 76.1 & 76.1 & 0 \\
$\mathrm{Ni}(\mathrm{II})$ & 227 & 22.6 & 22.6 & 0 \\
$\mathrm{Ni}(\mathrm{II})$ & 770 & 6.7 & 7.2 & +7.5 \\
$\mathrm{Cu}(\mathrm{II})$ & 46 & 22.6 & 23.5 & +6.2 \\
$\mathrm{Cr}(\mathrm{III})$ & 667 & 15.4 & 17.5 & +13.6 \\
$\mathrm{Fe}(\mathrm{III})$ & 46 & 22.6 & 24.0 & +4.0 \\
$\mathrm{Mn}(\mathrm{II})$ & 46 & 22.6 & 0.5 & -91 \\
& & & & \\
\hline
\end{tabular}


Table VI. Analysis of samples for cobalt

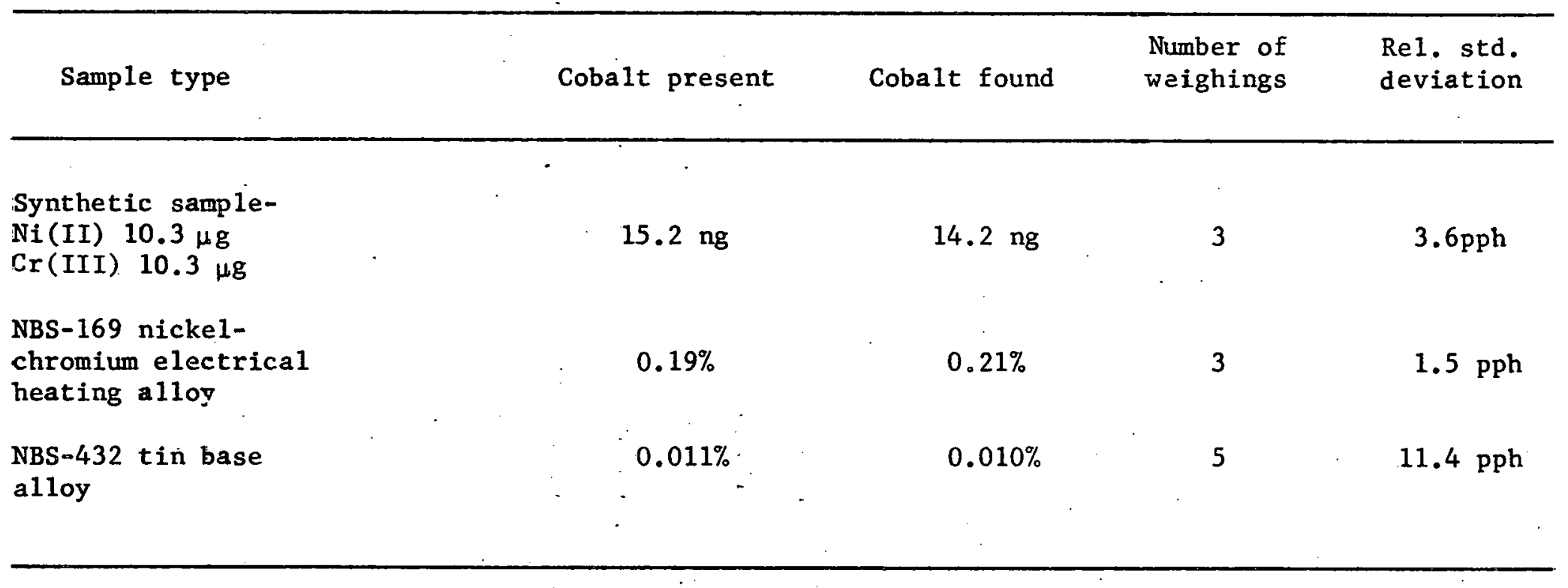


heating alloy containing high percentages of nickel and chromium, was dissolved in perchloric acid. It was filtered and taken up in $500 \mathrm{ml}$ of the sorbing medium. This solution was diluted by a factor of 3.3 before injection.

The chromatographic analyses for cobalt in the NBS samples compared favorable with the standard analyses. Thus, the method as described appears to be workable with these types of samples. Lower concentrations of cobalt can be determined by taking the sample up in less solvent, or by concentration of samples that contain metals not taken up by the column with the cobalt.

\section{Other Considerations.}

Simultaneous ultraviolet and chemiluminescent detection

Figure 12 shows a partial separation of metals on Bio-Rad AG 1-X4 using both chemiluminescent and UV detection. The conditions for each are the same except that for UV detection the column effluent was directed into a $z$-type $1-\mathrm{cm}$ path length flow cell (49) housed in a Heath EU-701 spectrophotometer.

No response whatsoever is noțed for chromium, copper or iron with chemiluminescent detection, nor are solvent change peaks observed. On the other hand, the UV detection of cobalt in hydrochloric acid is very poor. The wavelength and type of eluent are not optimum for the UV detection of copper, chromium and iron, but were chosen to demonstrate the possibility of obtaining additional information by coupling the two methods of detection. It should be possible to monitor a column effluent 


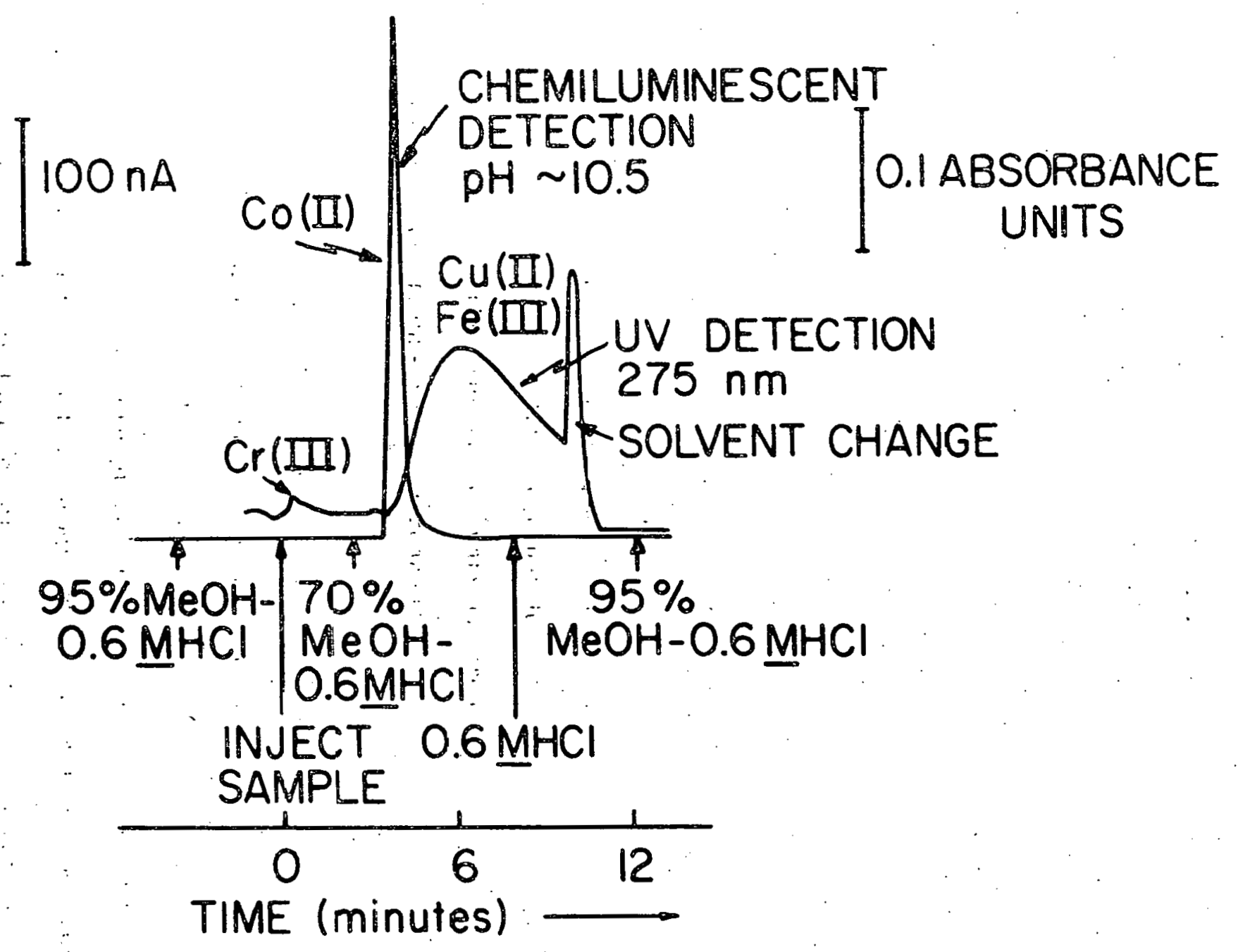

Eigure 12. Comparison of ultraviolet and chemiluminescent detection for the partial separation of $230 \mathrm{ppm}$ iron(III), $182 \mathrm{ppm} \mathrm{Cr}$ (III), $220 \mathrm{ppm} \mathrm{Cu(II)} \mathrm{and} 1.5 \mathrm{ppm} \mathrm{Co}$ (II) 
using both detectors in tandem and a dual pen recorder. The chemiluminescent detector would have to be placed after the UV detector due to its destructive nature. Limitations would have to be placed on the acidity of the eluent, and strongly chelating dyes could not be added to aid in the UV detection.

\section{Observations}

All the experimental work reported in this thesis was done with no special precaution taken to purify reagents or to ensure that trace contaminants were not present. Clearly, if chemiluminescent methods are to be used to their limit these precautions must be taken.

Solvent change peaks like those observed for ultraviolet detection were not seen, but changes in baseline upon changing the eluent were seen at the sentitive settings of the photometric readout module. Also, the background luminescence of different batches of eluent varied. This can be explained by the presence of varying amounts of trace contaminants in the eluents and light-producing reagents.

Another observation relating to trace level contamination is pictured in Figure 13. This figure shows calibration plots for cobalt observed on three different days. For the March 14 and March 17 plots, the same standard cobalt solutions were used. On March 19, new standards of the same concentration were prepared. The same eluent solutions were used on all three days. As time progressed the plot became increasingly curved. One possible explanation of this phenomenon is that the sorbing medium, in this case $95 \%$ methanol - 0.6M hydrochloric acid, was picking up 


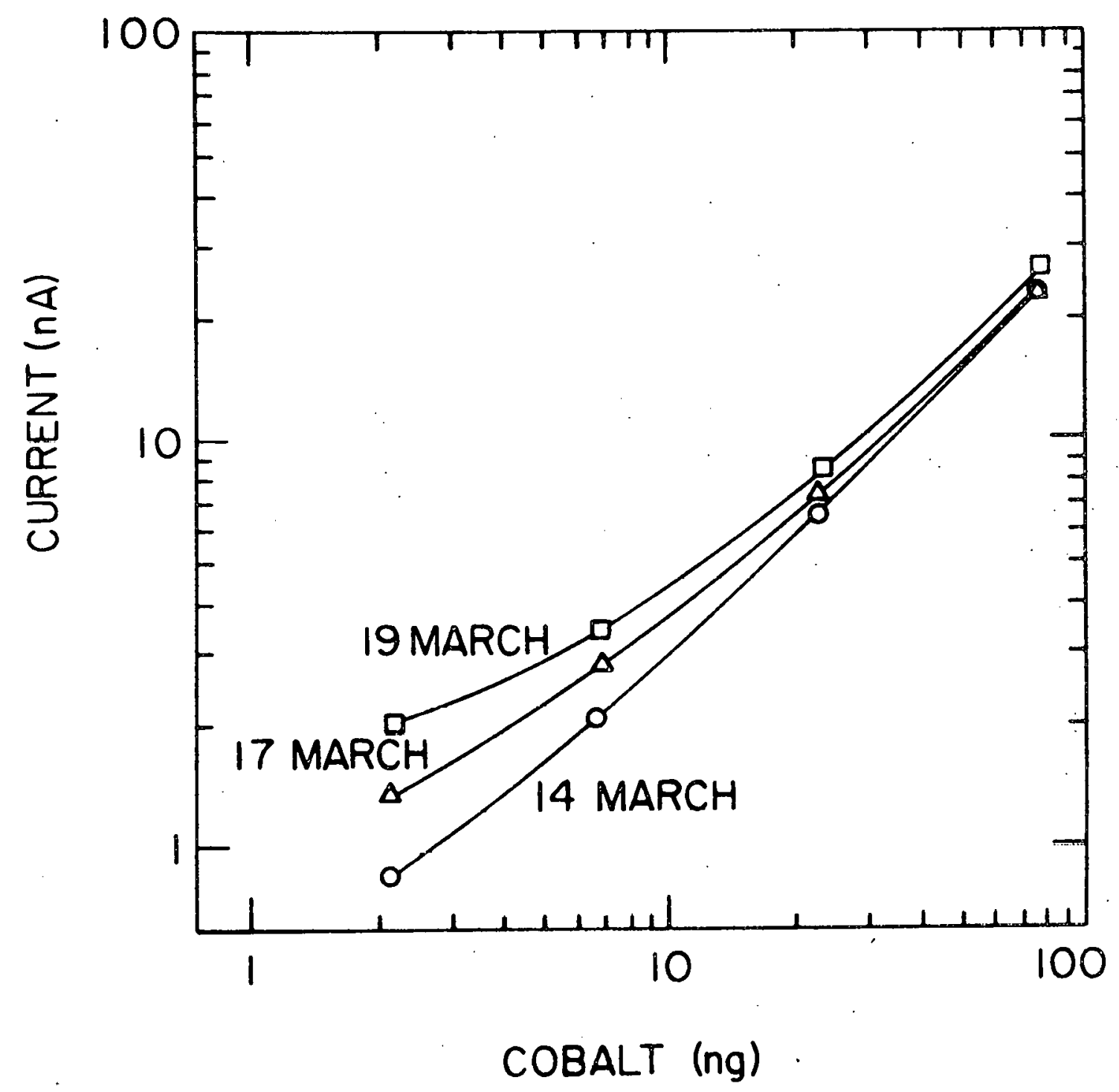

Figure 13. Change in calibration plot of cobalt with time 
metal ions from the container. These lons became sorbed to the column and then were stripped and detected upon changing to the eluent.

A third instance in which contamination was observed involved the pneumatically actuated injection valve. On occasion, peaks were seen when the valve was put in the "fill loop" position, especially when no column was in the eluent stream. When the fittings on the valve were washed, these "fill loop" peaks decreased somewhat. It seems likely that metal salts from the fitting washers found their way into the eluent stream during the switch to the "fill loop" position.

Elution of metals from a cation exchange resin

Figures 14 and 15 demonstrate the capability of chemiluminescence detection to monitor low level metal ion concentrations even when the distribution coefficients of those metals are high. The column was packed with 200-400 mesh Dowex 50-X8 resin. The eluent was $0.1 \mathrm{M}$ hydrochloric acid-0.4M sodium chloride. The flow rates were $0.80 \mathrm{ml} / \mathrm{min}$. and the $\mathrm{pH}$ was 11.1 . 


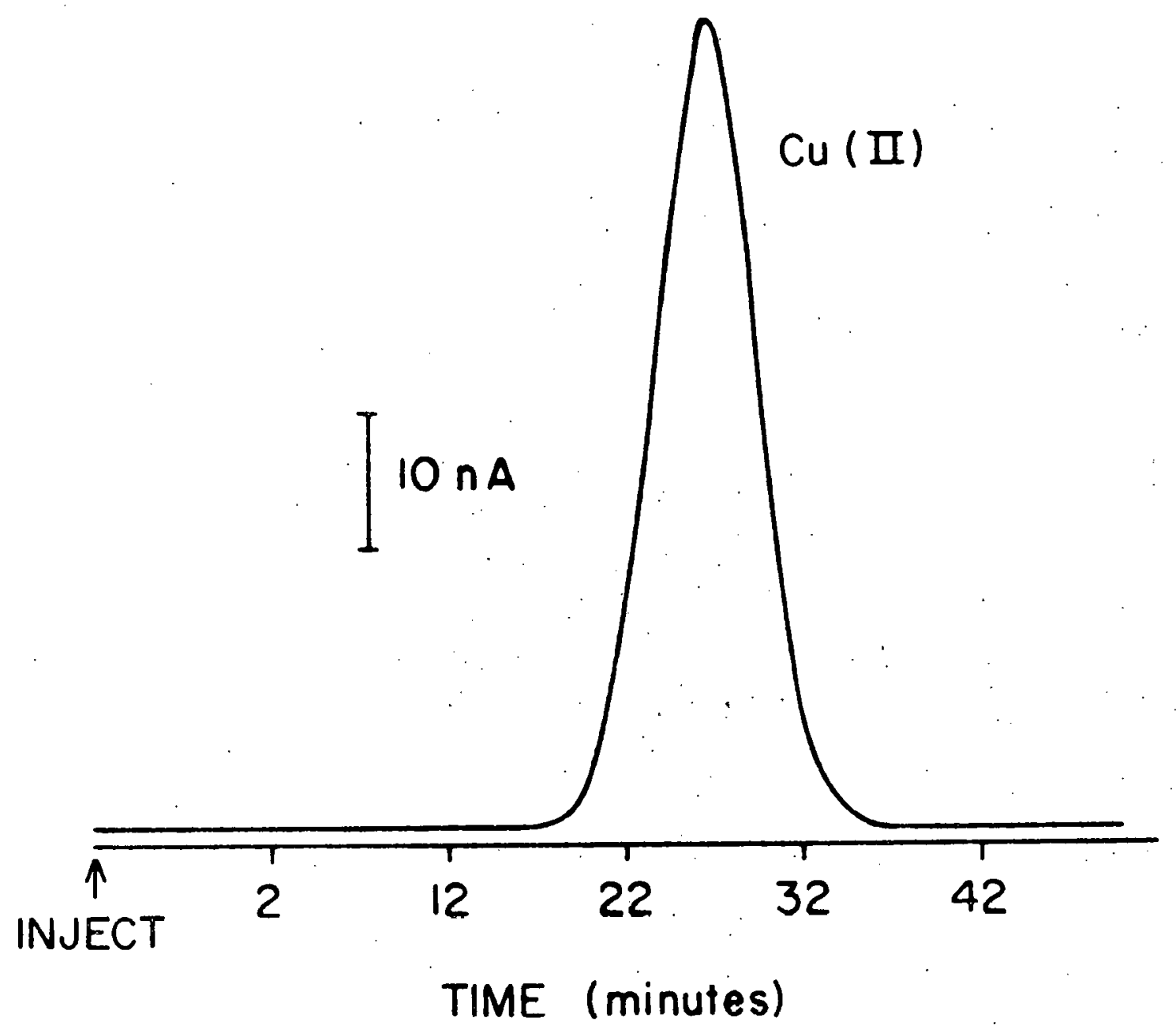

Figure 14. Elution of $5.1 \mu \mathrm{g} \mathrm{Cu}$ (II) from Dowex 50-X8 


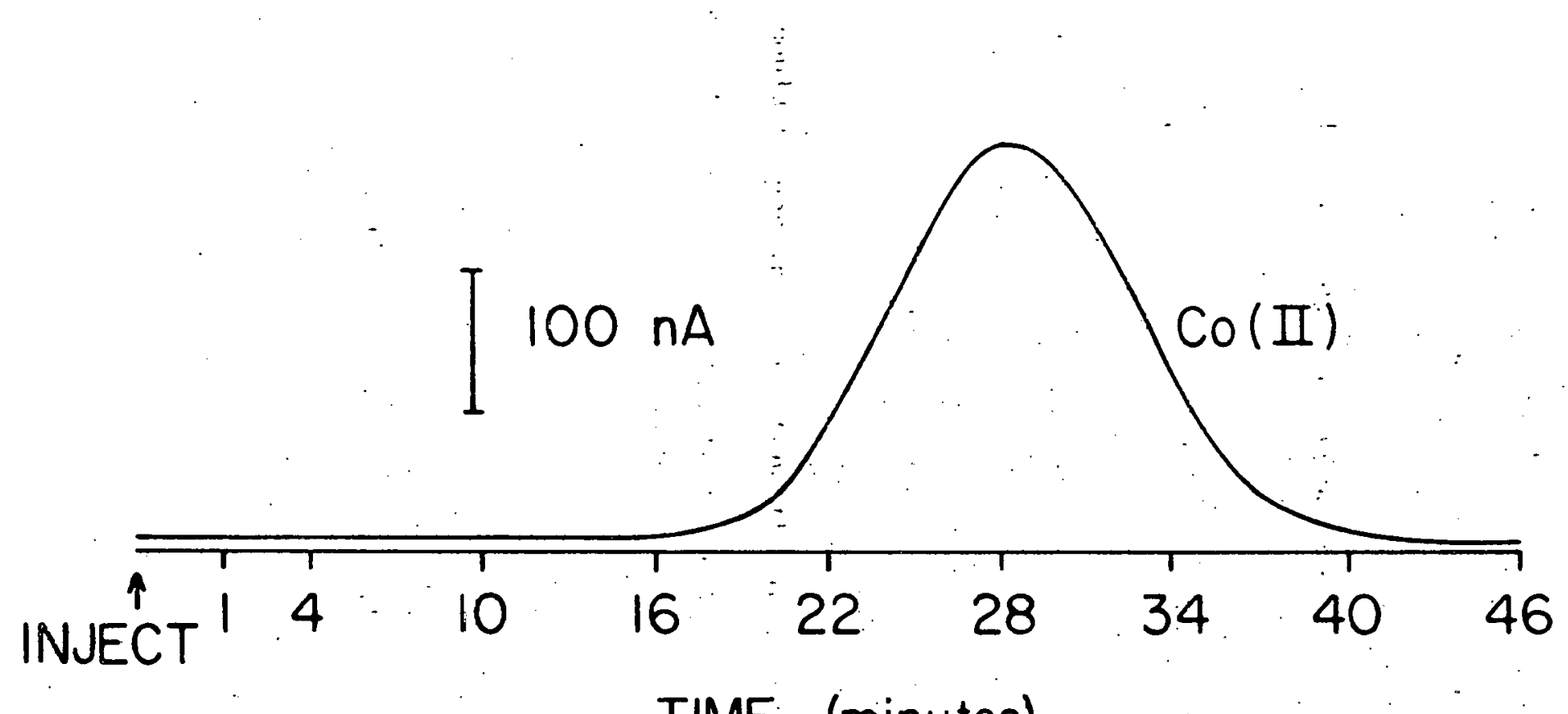

Figure 15. Elution of $51 \mathrm{ng} \cdot \mathrm{Co}$ (II) from Dowex 50-X8 
SUMMARY AND CONCLUSIONS

The application of the chemiluminescence of luminol for liquid chromatography detection shows promise for monitoring and quantitatively determining several metals at trace levels. This is further indicated by a recent paper by Hartkopf and Delumyea (50) that describes another chromatographic system utilizing luminol as a detector. The detection is selective for those metals that catalyze the peroxide oxidation of luminol. The $\mathrm{pH}$, flow rate, distance of the detector from the point of reagent mixing and the nature of the solvent all affect the luminol reaction and, thus, the intensity of the emitted light.

Problems relating to harmonizing eluent requirements for metal. separations and $\mathrm{pH}$ requirements of the luminol reaction are solved through the use of salts and organic solvents in conjunction with mineral acids.

It should be possible to extend the lower range of metal detectability with the use of highly pure reagents and by concentration of metals on a column.

The application of other chemiluminescent systems to metal detection in liquid chromatography should be encouraged. It may be possible to find a reagent which exhibits chemiluminescence in a medium more compatible with the separation of metals. 


\section{BIBLIOGRAPHY}

1. M. S. Tswett, Ber. deut, bot. Ges., 24, 384 (1906).

2. C. D. Scott, Anal. Chem., 44, 85 (1971).

3. M. D. Seymour and J. S. Fritz. Anal. Chem., 45, 1394 (1973).

4. S. H. Byrne, Jr., in Modern Practice of Liquid Chromatography, J. J. Kirkland, Ed。, Wiley-Interscience, New York, 1971 , Chapter 3.

5. M. D. Seymour, J. P. Sickafoose and J. S. Fritz, Ana1. Chem., 43, 1743 (1971).

6. M. D. Seymour and J. S. Fritz, Anal. Chem., 45, 1632 (1973).

7. R. B. Willis, Ph.D. Thesis, Iowa State University, Ames, Iowa, 1973.

8. J. S. Fritz and L. Goodkin, Anal. Chem., in press.

9. J. N. Story, Ph.D. Thesis, Iowa State University, Ames, Iowa, 1973.

10. D. C. Johnson and J. LaRoche11e, Talanta, 20, 959 (1973).

11. Y. Takata and G. Muto, Anal. Chem., 45, 1864 (1973).

12. N. Yoza, S. Ohashi, Anal. Lett., 6, 595 (1973).

13. T. W. Gilbert and R. A. Dobbs, Anal. Chem. , 45, 1390 (1973).

14. N. Yoza, T. Ogata, Y. Ueno and S. Ohasi, J.Chrom., 61, 295 (1971).

15. P. A. Nedermeyer and L. B. Rogers, Anal. Chem., 41, 94 (1969).

16. R. I. Pecsok and D. L. Saunders, Anal. Chem., 40, 1756 (1968).

17. E. H. White, O. C. Zafiriou, H. M. Kagi and J. H. M. Hi11, J. Amer. Chem. Soc., 86,940 (1964).

18. V. Y. Shlyapintokh et al., Chemiluminescence Techniques in Chemical Reactions, Consultants Bureau, New York, 1968.

19. E. H. White and D. F. Rosewel1, Accounts Chem. Res., 3, 54 (1970)。

20. J.W. Haas, Jr., J. Chem. Ed., 44, 396 (1967).

21. F. McCapra, Quarterly Revlews, 20, 485 (1966). 
22. H. O. Albrecht, Z. Physik. Chem., 136, 321 (1928).

23. A. K. Babko and N. M. Lukovskaya, Ukr. Khim. Zh., 30, 388 (1964); Chem. Abstr. , 61, 3677e (1964)。

24. A. K. Babko and N. M. Lukovskaya, Ukr。Khim. Zh., 27, 519 (1961); Chem. Abstr., 57, 1532h (1962).

25. L. I. Dubovenko and L. A. Pilipenko, Visnik Kiivs'k。 Univ. Ser。Fiz. Khim., 75 (1970); Anal. Abstr., 20, 33646 (1971)。

26. A. K. Babko and I. E: Kalinichenko, Ukr. Khim. Zh., 31, 1092 (1965); Chem. Abstr., 64, 9215g (1966).

27. A. K. Babko and I. E. Kalinichenko, Ukr. Khim. Zh. , 31, 1316 (1965); Chem. Abstr., 64, 13374므 (1966).

28. I. E. Kalinichenko, Ukr. Khim. Zh., 35, 755 (1969); Anal. Abstr.; 19,2231 (1970).

29. L. I. Dubovenko, Ukr. Khim. Zh., 35, 957 (1969); Chem. Abstri., 72, $36224 \underline{b}$ (1970).

30. L. I. Dubovenko and Ti Hun Chen, Ukr. Khim, Zh., 35, 637 (1969); Chem. Abstr., 71, 54723 x (1972).

31. A. T. Pilipenko, N. M. Lukovskaya and T. M. Bogoslovskaya, Otkrytiya, Izobret., Prom. Obraztsy, Tovarnye Znaki, 50, 213 (1973); Chem. Abstr., 79, 100243壬 (1973).

32. I. I. Dubovenko and T. A. Bogoslovskaya; Ukr. Khim Zh., 37, 1057 (1971); Chem. Abstr., 76 67862 (1972).

33. A. K. Babko, I. I. Dubovenko and L. S. Mikhailova, Zh. Ana1。Khim., $\underline{21}, 548$ (1966); Chem. Abstr., 65. 9715h (1966).

34. W. R. Seitz, W. W. Suydam and D. M. Hercules, Ana1. Chem., 44, 957 (1972).

35. W. R. Seitz and D. M. Hercules, Anal, Chem., 44, 2143 (1972).

36. W。 R. Seitz and M. P. Neary, Anal. Chem., 46(2), 188A (1974).

37. E. H. White and M. M. Bursey, J. Amer. Chem. Soc., 86, 941 (1964).

38. E. H. White in Iight and Life, Ist ed., W. D. McElroy and B. Glass, Ed., Johns Hopkins Press, Baltimore, Md., 1961, p. 183.

39. P. B. Shevlin and H. A. Neufeld, J. Org. Chem., 35, 2178 (1970). 
40. A. K. Babko and N. M. Lukovskaya, Ukr. Khim. Zh., 34, 1279 (1968); Chem. Abstr., 70, 109465b (1969).

41. W. C. Schumb et a1., Hydrogen Peroxide, Reinhold Pub. Corp., New York, N. Y., 1955 , pp

42. F. P. Dwyer et a1.., Aus. J. Chem., 12,,138 (1958).

43. J. P. Sickafoose, Ph.D. Thesis, Iowa State University, Ames, Iowa, 1971.

44. A. K. Babko and N. M. Lukovskaya, Zavodsk. Lab., 29, 404 (1963); Chem. Abstr., 3301d (1963).

45. A. K. Babko and N. M. Lukovskaya, Dopividi Akad, Nauk Ukr. RSR, 619 (1962); Chem. Abstr., 57, 14469g (1962).

46. K. A. Kraus and F. Nelson, Metal Separations by Anion Exchange in ASTM Special Technical Publication No. 195, American Society for Testing and Materials, Philadelphia, Pa., 1958.

47. W. R. Seitz. and D. M. Hercules in Chemiluminescence and Bioluminescence, M. J. Cormier, D. M. Hercules and J. Lee, Eds., Plenum Publishing Corp.., New York, N.Y, 1974.

48. J. Korkisch and I. Hazan, Talanta, 11, 1157 (1964).

49. M. D. Seymour, Ph.D. Thesis, Iowa State University; Ames, Iowa, 197.2.

50. H. Hartkopf and R. Delumyea, Anal. Lett., 7, 79 (1974). 


\section{ACKNOWLEDGEMENTS}

I wish to express my appreciation to Dr. James S. Fritz for his guidance and encouragement during the course of this work, and to Louise Goodkin for her many helpful suggestions. 